\title{
TĀTAI TARA \\ GENEALOGICAL STORYING: \\ A FOUNDATION OF DECOLONISATION IN OCEANIA
}

\author{
BY
}

\section{IAIN THOMAS STRATHERN}

(Ngāpuhi, Ngāti Ruanui)

A thesis submitted to the Victoria University of Wellington in fulfillment of the requirements for the degree of Master of Arts in English

Te Whare Wānanga o te Ūpoko o te Ika a Māui

Victoria University of Wellington 


\section{Ngā Mihi}

Many thanks to the office of the Pro-Vice Chancellor Māori for support through the Tu Horomata scholarship. I would like to acknowledge the guidance given by Jane Stafford during the writing of this thesis. Many thanks Jane.

To my tūpuna, Nana, Grandad, Tom, Grace, James, Marion, Dolly, Pita, Roka, William, Matilda, Maida, Ata, Arnold, John, Mary-Anne, Davis, Samuel, Ani, Esther, Robert, Erana, Kuki, Pehiriri, Te Moana, Te Turau; and to the tūpuna of my wife and children, thank you all for your lives, your stories, and your guidance.

To my two mums, Odessa and Carolina, with all my aroha/alofa - thank you. Though too early for us who are left behind, you have both earned your rest from this life. You are always in our hearts.

Dad, thank you for always being there, and for providing such stability-materially and emotionally —in my life. To my sister, Elisha and my brother, Mark, thank you for sharing the very personal journey that this thesis describes.

To my daughters, Odessa and Mara, thank you both for your patience and your love, girls. And to Elise, my amazing wahine, thank you for all your support and loving encouragement, and for bringing our girls into the world, carrying our stories into the future and into our past. 


\begin{abstract}
This thesis reads Patricia Grace's Baby No-eyes, and Albert Wendt's The Adventures of Vela and The Mango's Kiss to highlight the essential nature of tātai tara (genealogical storying) in the decolonisation of Oceanian identity. Central to the thesis is a personal mythology, a kind of memoir that recounts some of the author's foundational stories in the form of prose and poetry.

The first core chapter deals with a discussion of post-colonial 'skins', the things that we believe are part of ourselves that essentially come from being socialised in a colonial culture. The chapter "Skeletons", explores the family secrets that give rise to shame that is intergenerational. Finally, Flesh and Blood demonstrates the powerful nature of reclaiming family stories as a way of re-education and healing.

Ultimately, the thesis aims at an understanding of tātai tara, a process that happens whether we are aware of it or not, and how the individual is a creator of his or her own identity through the level of engagement with the stories.
\end{abstract}


Table of Contents

Ngā Mihi

Abstract

3

Table of Contents

4

Chapter 1

5

Ko wai tōku waka?

Chapter 2

13

Skins

Chapter 3

Skeletons

Chapter 4

Flesh and Blood

Chapter 5

Conclusion

References 


\section{Ko wai tōku waka?}

Essentially this thesis is concerned with the decolonisation of identity. This thesis aims to explore the use of tātai tara as an essential tool that is being used towards the decolonisation of the minds of Oceanian peoples. Tâtai (whakapapa) has been an integral part of decolonisation in our region since colonisation began. For as long as Europeans have been visiting our shores, there have been those who are resistant to their visits. Tâtai, the connections between us, our ancestors and descendants is central to such resistance because it is tătai that creates our identity, makes us who we are. It is well documented that colonisation has done more than alienate indigenous peoples from their lands. We have become alienated from ourselves. This is why there have been those who resisted from the start. The fear of change. If there is too much change then how will we recognise what is right and what is wrong? How will I recognise myself?

In Wiremu Grace's telling of Māui's early years, "How Māui got his name”, Māui reaches a point where he must go against his beloved foster father's desires in order to find out about his real parents and to find his true name. In doing so Māui reinvents himself from orphan "chosen and cared for by the atua" (3) to "Māui-tikitiki-a-Taranga; Māui of the top knot of Taranga" (5) The story turns its focus from the bond of love between a mother and her stillborn son as she sends him forth into the world in the top knot of her hair "fashioned as a waka" (3), to the child's connection to divine forces in his growth to adulthood, and then back to the bond of love symbolised in the hair of Taranga and her sons. It is a story of genealogy, genetics, and relationship through connected experience. Yet it is also a story of separation, loss, alienation and longing for identity.

The focus of this thesis is the relationship between story and tātai. Ranging from 'purely' fictional to mythological to 'documented historical', the stories within the thesis convey or contain an aspect of tātai that is often missed or at least made secondary by the most common Pākehā translation of the word 'whakapapa' - 'genealogy'. The word tātai is commonly preferred by iwi of Te Hiku o te Ika to the word 'whakapapa', and there are significant differences between the meanings of these two words. The definitions of tâtai according to John C. Moorefield's Te Aka Māori-English Dictionary (n.p.) - “(verb) ... to measure, arrange, set in order, plan, and recite (genealogies)" and "(noun) ... lineage, line of ancestry, genealogy" - are similar to those of whakapapa (n.p.) - "(verb) ... to lie flat, lay flat, recite in proper order (e.g. genealogies, legends, months)" and "(noun) genealogy, 
genealogical table, lineage, descent". Tātai, however, has additional layers such as its occurrence as the verb meaning "to adorn, to deck out, beautify" and as the noun meaning "arithmetic". Where whakapapa translates as the verb "to plan", tātai may be translated to the same verb or to the nouns, "purpose, plan, tactics", simultaneously evoking a sense of ongoing planning and a sense of a completed, fixed, plan and goal. Further aspects of the word tātai are seen in uses such as tātai pūmanawa, "curriculum vitae"; tātai pukapuka, "indexes, indices", tātai whetū, "constellation, cluster of stars" and tātai arorangi, "astronomy, knowledge of celestial bodies". The versatility of the word relates to the commonly held belief in te ao Māori, that all things, even the inanimate, have a tătai, this being so, the word is not exclusively used for human familial relationships as the English 'genealogy' and some other related terms tend to be. Whakapapa has a similarly versatile usage as one explanation of the meaning of whakapapa is that it is a layering one upon another. Whakapapa can therefore be utilised for lists similar to indices and CVs.

The difference in meaning then, seems to lie mainly within its use as the verb meaning "to adorn, deck out, beautify" and its association with the stars. Thus the whakapapa of the word 'tātai' connects to the genealogy of creation, via the story of Papatūanuku and Ranginui's separation by their son Tāne-mahuta and their children's subsequent adornment of them. While Papatūanuku is beautified with their mokopuna, the grasses, trees and rocks, Ranginui's blue cloak is, of course, decked out with the stars. Thus the word 'tâtai' embodies an essential aspect of Māori traditions of genealogy that may not be as apparent with the word 'whakapapa' due to its common usage in non-Māori New Zealand as a stand in for English words such as 'lineage' and 'recite (ancestry)'. Whakapapa refers not merely to the physical descent of individuals from their parents, but to the spiritual aspects of those relationships and to the relationships between one person and all that is in existence whether they be human, tree, rock or star. Furthermore such whānaungatanga means that human beings are descended from the sky and earth atua and further to the creator Io-matua-kore ('Parentless-Io' or 'Io-Parent-of-the-Void'). Tātai then is the web of relationships between the creator, creation itself, and the 'creation' of a certain individual person.

\section{He kōrero tara o te tìmatanga o te ao}

The 'creation' of an individual includes her unique story of the relationships between all her ancestors. They are unique and also repetitious; parts of them are shared most closely with their siblings, then with their parents and so on. In a sense then it is the sharedness of such stories that makes up tātai and it is this sharedness of stories, of ancestry, that finally 
returns us, full circle, to the divine. Stars guide us as navigators over land and oceans. As we look to the stars for guidance in the physical realm, we also look to our ancestors and their stories for guidance.

The challenge that colonisation represents to this way of seeing the world is one that continues to reverberate through generations of Māori, in their relationships in everyday life. A predominantly Anglo-centric worldview continues to dominate New Zealand society. As Konai Helu Thaman points out, New Zealand is not an unusual case amongst Oceanian nations, suffering this fate simply because Māori constitute a minority of the population. Even in those countries where the indigenous population forms a majority, the "formal educational institutions, particularly those of higher education, have not regarded Oceanic cultural knowledge, skills, and values as worthy of inclusion in academic study" (8). This has meant that indigenous ways of thinking have been invalidated and ignored by domineering and selfreifying Western scientific-industrial culture (Smith 1; Thaman 10). The thesis examines the significance of tâtai in redressing the impact of colonisation, and the subsequent domination of an Anglo-centric worldview, on the psychological health and well-being of Māori and other Oceanians.

\section{Methodology}

While the thesis does not dismiss linear approaches to knowledge it does demand the ability of the reader to embrace the possibility of more three-dimensional ways of reasoning. The tendency of the postmodern writer to aim towards fusion, ambiguity, and blurred lines, needs to be expressed in academic works that aim to elucidate the words of such writers. The first objection should probably be How can you elucidate something by copying it? How can you make clear by "blurring the lines"? My response to this is that I do not mean that academics should 'clarify' as in make things simple to comprehend, I think we all know that this is not our intention. We look at things in-depth, we look for the complexities, we make them up if we have to- the comprehension of others is secondary to what we do because primarily we are trying to find comprehension ourselves. When I talk about elucidating the words of postmodern writers I am talking about illumination, not simplification. I want to see the complexities, and I want to show others the way that I see them. Hopefully I'll make sense at the same time, but equally I hope that I will convey the complexities not just by pulling them apart and listing them, and explaining them (away), but by holding a mirror to them, and it will be unashamedly a mirror of my own construction.

While academia may benefit from attempts at objectivity and detachment, it can also 
benefit from acknowledged subjectivity and open biases. The 'myth' of the objective scholar is still strong, but at least it is acknowledged as just a story we like to tell. As this thesis aims to demonstrate, stories are powerful things and acknowledgment that there are powerful influences behind our words, actions, and beliefs is a powerful force too. One that may allow us, if not to free ourselves from them entirely, awareness enough to exercise some control over such influences.

The world is full of contradictions (academia is a testament to that) and as much as we strive to understand, label, categorise, and systematise, there is no way of solving all the contradictions, and anyway, why would we want to? Contradictions make the world a rich place to exist. They make the world sublime. They make it real and not real, extraordinary and ordinary, natural and supernatural. Of course the thing about the sublime is that it is not always particularly comfortable. Neither is change, innovation, difference, or Other-ness. But as humans we do it anyway, we live with the sublime, we make changes, we innovate, we encourage difference, and embrace Others in the best ways that we can. We don't always do it very well, partly because we are always resisting change, innovation, difference and Otherness. What is particularly interesting about this is that it means that embracing innovation is not innovative, it is tradition - our ancestors have been doing it for millennia.

So, I do not claim that this thesis is anything new or unique, everyone knows it's all been done before; the reason that we keep doing it all over again is that we learn by repetition. Much of the content of the thesis is a repeat of what I have done before because I lived some of what is represented here; by which I mean that some parts are autobiographical. And I have relived it often in my mind or in retellings of retellings. This is just another representation of that material. Even the stuff that I didn't live myself, that's all second-hand too. I lifted it all from other people's work. I hope that's okay with you.

Us, we, our

Within the thesis I continue to use personal pronouns informally. My reasoning behind this is that academic works should be as accessible as possible to aid their dissemination to as wide an audience as possible. I also trust the reader to use her own judgement where it is unclear who the 'we' I am talking about is. Absolute clarity of communication is as impossible as complete objectivity, so while my intent is not to be unclear, I am also not intending to be absolutely clear either. Use of unqualified personal pronouns in academic literature may be problematic, however it may be equally true that the assertion of scholars that it is problematic, is the problem. As literary critics, we question 
anomalous uses of personal pronouns, there is reason for them, surely, and we endeavor to discover their purpose. Clarity of differentiation, in a scientific-academic sense, is a myth of scientific rationalism. Rather than continuing to espouse such a myth I prefer to challenge the reader to embrace the opportunity provided by ambiguity to examine the possible connections that English pronouns such as 'we' represent.

\section{Further Acknowledgements}

From the very outset of the thesis I wish to acknowledge the position from which I write. My ancestry plays a major role within the thesis and with it comes a number of biases which both complicate and clarify the statements that I make here. By birth I am Māori (Ngapuhi and Ngati Ruanui) and English (Kent and Dorset) on my mother's side. On my father's side I am Scots (Clydebank) and Irish (Donegal). My upbringing, however, favoured one culture over the others. English was the primary language spoken in our home. Most of the customs we observed in our domestic life and in our predominantly Pākehā community were also English. Yet my red-headed father with his Scots accent was easily identified as being a non-English recent arrival in Aotearoa, and my mother, by any outsider, would have been identified as Māori. Neither of my parents identified themselves how others would have identified them. My father, from the moment he was naturalised, considered himself a 'Kiwi' - a Pākehā New Zealander - and Scotland has been a distant shore for which he has no longing. My mother's upbringing was rough, abusive, traumatic - a fact which allowed her to leave behind anything she identified as belonging to Māori culture. Except of course her skin. It is from this position that I write, and I am aware of many of the biases that come with this position, and I am aware that I am not, and can not be, conscious of every single one of them or of all their effects upon this body of work. I acknowledge this limitation as one who must acknowledge that the sea, no matter how familiar he becomes with it, holds certain limitations for him. Even as a learned navigator the limitations, while reduced significantly, are not eradicated.

\section{He Patai}

Patricia Grace and Albert Wendt use Oceanian concepts of genealogy to express a particular worldview, and significantly to challenge the Eurocentric epistemologies that continue to dominate the region. The thesis is primarily concerned with what this actually means in practical terms for readers, and more widely for Māori and other Oceanian communities. How does an person's engagement with tâtai, be it their own or be it fictional, 
contribute to the decolonisation of Oceania?

\section{Chapter Breakdown}

In Patricia Grace's works tătai, is both a verb and a noun, it is the planning, the tactics and the purpose. It is also the act of adorning the plan. It is the means to an end and the end in itself. It is method and the meaning. Tātai is used to tātai. And we tātai to achieve tâtai. The method, is tātai tara, narrating tātai. And the end is tātai tīnana, embodiment of tātai.This helps to satisfy a desire to see ourselves as Māori in the stories we read, a desire that Grace acknowledges as one of her inspirations for writing. One of her hopes, is that increasing numbers of Māori writing from our various perspectives will offset certain stereotypes of what it is to be Māori (1978; 83). Chapter Two, SKINS, explores the social shaping of Oceanian self-images in face of dominate Western worldviews that do not recognise the validity of other, particularly indigenous, ways of seeing. Absence of narrative tâtai creates a liminal existence for the individual, and as the thesis points out, this creates liminally existant communities. Thus the thesis speaks directly to issues of indigenous marginalisation. Within this marginalisation we find problems of drug abuse, violence and crime-each of which may be considered a form of violence against the self, the family and the community. The purpose of the thesis is to address these issues in relation to what I see as one of the most influential causes - that is the absence of or gap in narrative tâtai in the lives of many Oceanians that leads to a lack of engagement.

The chapter begins with a further examination of the pūrākau of Māui's beginnings, to introduce the concepts of personal 'creation' stories and self-mythologising as aspects of tātai tara. Using Thomas King's premise that "the truth about stories is that that's all that we are" (2003), the chapter takes a look at how we as individuals story our own identities, creating our own world, and how our most personal stories, that is, the ones attached to our genealogy, are the most influential in this process of world-creating. Following this, the chapter uses a 'real-life' example to explore the implications of this function of tātai on real lives. The example used is the story that I consider my own personal creation story, te tīmatanga o tōku ao. It is the story of my mother Odessa's death at the age of 33, pieced together from what I have been told by various relatives, what I have read in an article published in The New Zealand Listener about her death. It also includes what I have discovered about her other life (the one that came before my dad, my brother, and me) as I have tried to move forward with my own other life - the one I live in partnership with my wife Elise and our children, Odessa and Mara. The third part of the chapter will move into the 'fictitious' worlds of Patricia 
Grace's Baby No-eyes (1998) and Albert Wendt's The Mango's Kiss (2003) and The Adventures of Vela (2009). Each of which features episodes based around confrontations between beings of contrasting skin colour. Far from simplifying issues, these episodes, by drawing attention to skin in such interesting and unexpected ways, each bring a fresh and complex perspective to the conversation. The comparative reading of these three works, is inspired by the article by Chadwick Allen, Rere Ke/ Moving Differently, in which he comparatively examines works in English by Māori and Native American writers. By doing so he reveals a series of insights which may not have been apparent in reading the works of each ethnic grouping separately. Similarly, exploration of Grace's and Wendt's works together draws attention to themes and metaphors of each text that might easily be overlooked in individual readings.

Chapter Three focuses on the interaction between culture and the physical person and how this often creates what I call Skeletons, shame, fear, non-belonging, liminality, marginalisation and destructiveness. The layers of identity that are tātai are cultural-genetic combinations. Aspects of the society one is brought up in add to the layers of genetics. The cultural layers alter the individual from what we might think of as an inherited genetic 'blankcanvas'. Sometimes the layers are contradictory. Sometimes the social layers override the familial ones or vice versa creating an individual whose beliefs and values may contradict one another. Values battle it out inside the individual often without their awareness, sometimes creating an underlying disharmony and identity issues. Sometimes, though the battle may be even more guerrilla-style, with the ruling forces unaware that they even have any force opposing them at all. As far as they are concerned they are simply unchallenged autocratic rulers. Underneath the individual's despotic rule of herself, however, lies a number of skeletons, possibly of enemies that her mother never told her even existed, or ones she forced down there without having even noticed it herself. These skeletons are not a passive pile of bones, they are "lurking inside" like Wendt's vampires in "Towards a New Oceania" (73). Like all well hidden secrets they are subtly but powerfully influential. They rise from the pits well disguised, appearing not in the least skeletal, rather, they will look reasonably (if not completely) socially acceptable, respectable even. Their activities nonetheless are disturbing. They undermining the whole social fabric, causing fires that seem to have come from out of nowhere and landslides that seem completely natural.

Chapter Four deals with how reintegration of tātai tara helps an individual to heal and relates the individual healing to social healing - how healing individuals helps to create healing for communities, and what this might look like. It will also bring together the ideas of 
restoration and storytelling in the term 'restorying' which in effect is a new-old way of healing and maintaining social health which both restores original condition and changes (the meaning of) that original condition. 


\section{SKINS}

\section{The figurative and the littoral}

Exploring post-colonial Māori culture, I find myself looking more often in the mirror than to some one more expert than myself. I have after all lived this culture for thirty-five years now. In saying that, I didn't know I was living it, didn't grow up with the reo or the tikanga. For many of my formative years I lived in Australia were I had no contact with other Māori apart from my brother. In fact, I didn't even know we were Māori. My skin never mentioned it and neither did anyone else. My step-mum, Carolina, brought me up from the age of five or six, and her brown Sāmoan skin, was as close to looking Māori as our family came. Of course none of that mattered too much then; I was well looked after and very happy in my home life. However, I always felt there was always a bit of a gap, something missing, and it had to do with all that Māori stuff I saw on TV, I loved all that stuff that I saw through that window into the world, other worlds. Thirty years on I can see a bit clearer what might have happened in that small boy's mind. The association was made between Māori cultural forms such as waiata and haka, as seen on TV, and my other brown-skinned mum, the one who had been around up until a few months before I turned five.

So how does that add up to thirty-five years of post-colonial Māori culture? Well, I don't claim to have experienced everything that Māori culture has to offer, not even what post-colonial Māori culture has to offer. I only have a certain, specific experience of what it is like being a Māori in the post-colonial world. By post-colonial I mean since colonisation began, and I do not imply in any way that it is over, that somehow we have moved beyond it, gotten over it, started afresh. I only just 'found out' less than two years ago that I am Māori. I suspected it for a long time, even claimed it tentatively once or twice but with suspicion of myself. What if its true that Mum was Spanish / Indian and here I am pretending to be Māori? So I stopped pretending, I'd never know for sure anyway and I couldn't live claiming something I was that unsure of. But life kept pushing me to confront it. The feelings wouldn't go away by ignoring them. Such anger about colonisation and racism, where did that come from? I couldn't see it in any of my other family members. And there was always the gap, that something missing.

So how does all this add up to thirty-five years of post-colonial Māori culture?

Maybe it is the terminology. How about 'thirty-five years as a Māori living in a skin of 
'colonial culture'? Wearing their clothes, living in their houses, driving their cars, and looking at the brown skin of the hands gripping the steering wheel and seeing how it doesn't fit in. Better placed in a grass skirt, grass hut, holding an oar. Or looking at the white skin of the hands and seeing how it does fit in. Fits in too well, in fact makes you invisible, perfectly camouflaged, camouflaged enough to hear the jokes, the ridicule, the venom.

Culture is like a skin, we grow up already in it. We don't see it until faced with a person of a very different one. We can love it, hate it, be attracted to it, repulsed by it, we can ignore it as if it doesn't exist, but we can't live without it. We can even change it, manipulate it, graft it, embellish it, and of course destroy it. But skin is pretty tough for something so sensitive and flexible. Skin is about identity; consider the idiom "thick-skinned", used to describe someone who is not easily offended; or "she's comfortable in her own skin", for one who is confidently herself regardless of what others might think; and "I nearly jumped out of my skin", used when one is given a fright. What all of these have in common is the existence of an external force which is, at least potentially, able to influence the emotional equilibrium of an individual. The skin is a protective layer, that can be think or thin, and in which one might feel at ease or uncomfortable, and it is also a layer which one might be forced out of - a situation which would leave one more vulnerable.

The chapter also deals with skins in the sense that has been used to identify racial groupings. In this sense of the word we have the littoral, physiological meaning of "epidermis" and we also have another figurative or cultural meaning. The phrase "the colour of a man's skin" hold connotations of judgement and discrimination based on an outsider's perception of a individual's ethnicity. Thus "the colour of a man's skin" may mean both the actual colour of his skin, and at the same time other characteristics, such as the shape of his face / nose / eyelids / mouth, the colour and texture of his hair, the size and build of his body, his language and accent, the food he eats, to whom he speaks and the way he behaves. These visual and audial signs often lead to a reading / judgement of where the person is from, as well as what kind of person they might be, their social and financial status, what their spouse might be like, what their children look like, what they think about human rights, whether they are religious, and even whether or not they like football. In effect "the colour of a man's skin" often stands for who he is. It is here that the purely figurative meaning of the word 'skin' meets the littoral 'epidermis' - that outer most layer of who we are. It is the margin between individual and the rest of the world, or in other words, it is what connects the individual to the outer world.

The skin then is both separation and connection. When we think of this in terms of 
genealogy, we may automatically think of the inheritance of skin colour from one's parents. Having the same skin colour as one's parents separates us from people with different skin colour just as it connects us to our parents and wider family. Within the racially divided society that we live in in present day Aotearoa the skin often still speaks in place of who he is. Within this society there are other skins that we wear also. These are the skins of socialisation, of our cultural understanding of ourselves and the world. I call them skins because theses are the layers of Self that are laid over us or that we lay over ourselves. They become such an 'integral' part of who we are that we do not recognise that they came from outside ourselves. The story of Māui's origins, his own creation story, is one that may help us as Māori to think about this side of tātai where the physical, tātai tinana, our embodied genetic inheritance, meets what I call narrative tātai, or tātai tara, family stories.

Like a skin Tāranga's hair is a physical covering to protect the baby from the elements and provide warmth. Moreover, it acts as a spiritual amniotic sac, that provides connection with and nurturance from his mother. When Māui is 'born' a second time, that is when the old tohunga who finds him washed up lifts the child from the sea, the tikitiki, is not mentioned again and the child is in the realm of learning, discovering the world and his relationship to it. The tohunga teaches Māui about the connections between a man and the world. Māui is educated about the whānaungatanga that links him to natural world and to the atua. However, the old man is unable to teach him the lineage by which he might trace that connection generation by generation. This will be the next stage of Māui's life. He must go back out into the world (with the new 'skin' he has acquired from his foster father) to see if he can discover his more immediate origins. In Wiremu Grace's adaptation of the tale, when Māui first encounters other people he is "amazed at the different people he saw; children, women, boys, girls, and strong warrior men" (4). This one line expresses the sheltered upbringing that Māui has had, and implies a question about where Māui fits in in relation to these people. The explicit classification of men as "strong warrior[s]" may hint at Māui's desire to be like these men, to find his place in the world, and a willingness to don another new 'skin'. But of course what he really journeyed so far to find was the story of his actual skin (that is his tâtai tinana). At his first sighting of her, Māui recognises his mother. This could easily be explained by his recognition of facial features, yet the recognition comes rather through hair. Not even by his mother's own hair but through the hair of her tamariki, the 'skin' that she has given to them just as she gave Māui her tikitiki: "The young boy skirted through the shadows until he was close enough to see Taranga as she brushed the hair of her four boys in the firelight. The young boy knew instantly that this was his mother" (4). With this knowing comes a fuller 
realisation of who he is himself. At the most basic level Māui's realisation might run something like this: 'here is the woman from whom I was born, I am her son; she has four other sons, I am their brother; and she loves them and brushes their hair, as her son I am also loved'. Reading the hair-brushing through the lens of tātai tells the story of the bonds of love and nurture in the relationship between mother and sons. It draws attention to Māui's loss in this regard - his hair has never been brushed by his mother-and therefore the significance of having this gap filled. He received only limited love and nurturing via his mother's gift of her hair.

In one sense Māui did grow up having his tātai, for, as Taranga's actions at the outset remind us, tātai is very much a thing of flesh and blood—and hair. Therefore, Māui had his tātai all along, in every strand of hair and every fibre of his body. In another sense however, it is equally true that Māui grew up without his tātai for he was outside of his family, his village, outside of his ancestral knowledge, outside his mother's embrace and her ability to nurture and transmit to him knowledge of his family connections.

This kōrero tara gestures toward the dual nature of tātai in its physical, flesh and blood, origins and its constant renewal through memory, in the form of story. I use the word 'story' here because it expresses the opportunity to interpret and reinterpret - a connotation that is perhaps less apparent in either of the terms 'family history' or 'recitation of genealogy'. Family-stories include such recitation but also extend beyond this recitation to become examples by which to act in the world, ways of interpreting events and encounters, and modes of connection to supernatural power. Thus the absence of tātai (in either sense) translates into an inability to exist in the 'material' world-made up of the physical, emotional, psychological, intellectual, social and spiritual as it is. The absence of physical tātai means no physical existence even if the wairua or spirit knows its connection through story (assuming this is possible). And one who knows physical tâtai but lacks narrative tātai is unable to story him or herself effectively in this world. Either absence creates a liminal existence for the individual, and as the thesis points out, this creates liminally existant communities. Thus the thesis speaks directly to issues of indigenous marginalisation and the problems of drug abuse, violence and crime therein. The purpose of the thesis is to address these issues in relation to what I see as one of the most influential causes - that is the absence of narrative tātai in the lives of many Māori.

Creating a personal mythology is something different to writing an autobiography. In effect we do this as a matter of course throughout our lives. Experiences turn into retellings. And the retellings in turn create new experiences. A personal mythology is an essential part 
of narrative tātai. Like genes do physically, tātai tara situates an individual in a certain place and time in relation to his or her ancestors. Where autobiography is like the shell of a hermit crab, a personal mythology is more like a skin. Human beings out grow their autobiographies, while personal mythologies grow with the individual and with their descendants. The personal mythology is a work in progress, one which will never reach its end. It is created over a lifetime but not confined to that lifetime. It will be inherited and will become part of another life history in the making, just as it incorporated the stories of those who came before. Like myths and fairy tales, a life can have more than one reading, and various readings may be popular in different periods / life-stages. Myths and lives also have in common the nature of their construction. They are developed layer upon layer over long periods of time. Of course, when I say long periods I mean in relation to two different scales of time; one being human history and the other an individual's lifetime. These time scales are obviously interactive as are traditional myths and personal mythologies: both help us to explore the interface between ourselves and the world, helping us find meaning in this dynamic relationship.

\section{Māui at the interface}

Māui revelled in the position he found himself in when he rediscovered his whānau. Famously, his status as the pōtiki, the last sibling, helps to shape his relationships with his mother and his brothers, as well as with the rest of the world. The confidence with which Māui takes his place amongst his brothers, foretells of the self-assurance with which he will tame Tama-nui-te-rā, fish up one of the largest Pacific islands, and meet his end by attempting to win immortality for humanity. As anyone familiar with Māui's later exploits knows, the significance of his position as pōtiki is not to be underestimated. It becomes the other epithet by which he is known, Māui-pōtiki, as it matches his special and marginal position amongst his brothers, and challenges the accepted status of the eldest as kaiarahi. As the pōtiki, Māui's extraordinary strength and ability is even more incredible than if he were the mātāmua. Coming to know who he is and where he fits in (and how much he sticks out), Māui does not hide his light as one might expect the 'outsider' to do in order to gain acceptance from his brothers. Rather he baits them every chance that he gets, revelling in his lowly status and obvious superiorities.

Māui's foundational story is the journey from dependent babe nurtured in his mother's womb and after birth in the figurative womb of her hair, to child out in the world, discovering the world beyond his mother. From this motherless world, he returns to find his family and 
his role in the world. Reading this kōrero tara (also known as pakiwaitara or pūrākau) as a model of human development, we might recognise that separation from the family, particularly the mother, is an essential part of maturation, as is a return to them.

The return to the family is not merely a physical one, it is a return to the realm of family stories. It is here that Māui finds out who he is and who his parents are, and it is also the realm in which he stories a new chapter for the world, bringing longer days, land and fire to humanity.

\section{The Truth about Stories}

The stories of my youth, like the story of Māui's early years, provide a platform from which I move into the world, but before jumping into those stories, this chapter discusses the importance of stories in creating our world. The basic premise behind this discussion is borrowed from Cherokee author Thomas King and his book The Truth about Stories, an informal critical text that has perhaps influenced the formulation of the thesis more than any other single work. King weaves together stories from a variety of sources connecting them with one common thread, that is: "the truth about stories is that that's all we are"(32). The chapter will then concentrate on the effects of my own personal 'creation story' - what my life has become and continues to become as a result of the loss of my mother in my early years. Here I identify the world that I have created with this story as the foundational source and I discuss how this shapes my everyday life.

Thomas King uses the particularly relevant and persuasive example of creation stories to illustrate his point that the stories we tell create our realities and our identities. He juxtaposes the Native American story of the woman who falls from the sky with the story of Genesis (10-25). In his retelling of a Native American creation story where all of the elements of creation - the sea, animals and birds and the woman — work together, he emphasises that it is a story of optimism, cooperation and resourcefulness. The protagonist of the story, "Charm", is a curious woman who falls through a hole she has dug, through space towards a world entirely made of water. The sea birds make a net with their bodies to catch her before she hits the water and she is laid on the back of a turtle. With the help of the other sea animals Charm creates land from some mud that is found in the vast depths. Charm, who was already pregnant on her arrival, gives birth to twins; "A boy and a girl. One light, one dark. One righthanded, one left-handed. Nice looking babies, said the Cormorants, hope they like mud. And as it turned out, they did" (19). The twins make the landscapes of the Earth, the forests and the waterways, each of them adding their own polarity to the world, each one's work 
complimenting the other's. Reading this story in terms of individual growth and creation of identity or self, we might see the mud as the raw elements that we inherit from our parents and ancestors, from nature and the spiritual world. The child brings unique personality traits as represented by the qualities they are born with- "A boy and a girl. One light, one dark. One right-handed, one left-handed". In accordance with these unique qualities they shape their world/reality/self in their own image, we might say. The individual is in constant negotiation with the world and all that it contains.

This story is juxtaposed with the story of Genesis, in which humanity and the individual are shaped in the image of God and have no input into what their world/reality/selves look like. When they do shape their destiny in the one possible way available to them they are punished and separated from the divine source. Thus humanity's freewill and ability to shape its own destiny is seen as an undesirable and destructive quality. Genesis, King asserts, is a story where humanity fails to keep a covenant with an almighty god who then sends them out into the wilderness to toil and labour for the rest of their days. This move into the wilderness is followed by the story of Cain and Abel-brother against brother, murder, and deceit. The Native American story is little known whereas the latter is familiar even amongst people of various faiths. The reception of such stories may be another point of difference the former being received perhaps as a quaint and interesting, if somewhat childish piece of mythology (22). While Genesis may be seen as an allegorical tale of the reality of the human condition - the constant battle between the god of all that is noble, truthful and good, and the material, earthly, sinful qualities. There are different ways of looking at the world and how seriously we take stories. Stories we tell have varying degrees of influence but we are able to choose what we do with these stories.

\section{Ko Odessa tōku whaea}

I have been process of working out what to do with the following story for the past thirty years. My mother, Odessa was born in 1949. Her childhood was full of abuse of all categories and she was removed from her mother at least once temporarily, and finally when she was nine years old, for good. She was placed with a loving foster family with whom she lived until her mid-teens. Her foster mother related the story of Odessa's separation from her mother and her foster home placement to my brother, Mark in 2001. He recorded what Val told him on paper from the Calypso Hotel on the the Gold Coast in his distinctive handwriting, in a simple honest tone, like that of an historian. It was the first real information we had about our mother's life before she met our father and what Val told, and what I read 
on that hotel stationary, was the basis of a new understanding of Odessa and the life that I had inherited from her.

Here is my retelling of Mark's account as I recall it: Odessa took herself to a schoolholiday craft programme that was run by a woman named Val and her husband, Cyril. Val recalled Odessa's quiet enthusiasm; she was the only child to come everyday of the programme, in fact she was the only one to turn up for the last day, which was a bible class so she had Val and Cyril all to herself. They talked about Odessa's life at home with her mother and I imagine that they also talked about God. I wonder if this was an awkward one for Val: bringing up God - such an intangible - to a girl whose life had so far been full of the most tangible abuse and pain, God who works in mysterious ways and may choose not to change Odessa's situation. Or perhaps Val's faith was such that she may have seen God at work in their meeting and spending the day together. As it happened that day was the beginning of Odessa's new life. Val invited her to come over to their house after school sometime. The next day, just after three o'clock, a small figure was seen hovering at the top of the driveway. Odessa spent many hours at Val's house over the following weeks.

One day soon after, a distraught Odessa was asked by the school Principal what was wrong and what could be done to help her. Odessa told him that she had found a family that she wanted to live with and a meeting was set up with Val, the Principal and a Social Welfare Officer. I do not know the details of that meeting but the things that Odessa told them were sufficient for her to be instructed not to go home after school but to go with Val, and her belongings would be retrieved by Social Welfare. Odessa was to live with Val from then on. I can only imagine the mixture of fear and relief that Odessa must have experienced that day and the breaking point she must have got to in order to reach out as she did.

Of course, this was not the end of Odessa's trauma and struggle towards adulthood. Val, who had believed herself unable to conceive, became pregnant when Odessa was in her mid-teens. Odessa was reminded of her own mother who had so often been pregnant when she was growing up. She now looked at Val in the same light and became suicidal. After her second attempt at taking her own life Odessa was removed from Val and Cyril's care. She spent time at a psychiatric hospital in Porirua and was moved into a new foster home in Masterton. On completing her schooling she moved to Wellington to go into nursing. There ends Val's part of the story as recorded by Mark. The next episode of Odessa's life was recounted to me by my dad for the first time when I was about 18 years old (1996).

Odessa was working in Lower Hutt Hospital when she met John Strathern, a patient who was recovering from a car accident, which nearly took one of his legs and almost his life. 
As he recovered, his sense of humour, positive attitude and enjoyment of good conversation, found a match in Odessa's personality and after his discharge they met one night in the King's Cross Hotel. Still hobbling around on crutches, John bought her a drink and the romance began. Odessa and John were a match in many ways, they enjoyed a good time and were well liked in their social circles, they were also very different in many ways - probably most significantly in upbringing. John grew up in a financially well-off, working class home in Clydebank, Scotland. It was stable and loving as far as Edwardian/Victorian-style Scots families could be. His father, John, or Jack as he was more commonly known, was a welder and a member of the British Communist Party, who had been brought up Protestant. His mother, Cathie, was Catholic born to a Protestant mother and Irish Catholic father. The religious politics of John junior's family and Scottish society in general influenced his atheistic beliefs. In his 20s he had become a Pattern-maker and had been moved to New Zealand by a company who needed skilled workers in the 1960s. Odessa's broken home, brown skin and religious beliefs were in stark contrast to all this. Yet they married in the St Martin de Porres, Catholic Church, in Lower Hutt in 1972. I have seen some photos of the occasion: the white veil and dress over black hair and brown skin, the long train being carried by my (then) little cousins in yellow dresses; next to her a red-headed, red-bearded man with white skin dressed in a black 70s style tuxedo and bow-tie. They stand outside a Catholic church that has a large stained glass front depicting the black-skinned St Martin de Porres dressed in the habit of a Dominican brother, holding the bible and a crucifix. St Martin de Porres, orphanage founder and patron saint of health care practitioners and people of mixed race.

St Martin had been canonised just 10 years before that photograph was taken, even though he was born almost four hundred years earlier. Born in Lima, Peru to a freed Panamania slave and a Spanish nobleman, a mere forty-six years after Francisco Pizzaro executed the last free-reigning Emperor of the Incas, Atahuallpa. While the Spanish continued to build their colony from the new city of Lima, Martin de Porres was born. His mother, Ana Velazquez, being of African and possibly Native American descent, Martin was considered a mulatto, 'mixed-blood'. The etymology of mulatto connects it to the latin mūlus, 'mule' - the offspring of a male donkey and a female horse (Barnhart and Steinmetz 684), and there are anecdotes told of insults Martin suffered as a result. Yet he reportedly used the term himself when his priory was in financial difficulty, imploring the order to sell him because of his status as a mulatto. All of this in a photo from 1970s suburban New Zealand. New Zealand-where my mother had learned to be ashamed of the colour of her skin and had 
thanked my father's white-skinned parents for their acceptance of her-a place perhaps not so far from 1570s Peru. In that photo also, my father's denial of the spiritual, my mother's uneasy relationship with the Catholic Church, and the religious bigotry of my Scots-born family not to mention the entire history of human migration and colonisation.

At dusk the silhouettes

of pines fringe the top

of our hills

like some black lace border on the mourning-dress of our whenua/

after

birth/

death/

nears

the black clouds

bringing the rain

that sparks a bush fire in the dark

for your sparking eucalypt leaves are alight with the rain of suburban Aotearoa/ what koori demi-god hid Mahuika's secret in your branches for eternity?/ your desire to burn is not dampened in your misplacement by the migratory manuhiri/ who have come to stay/

I know your spirit when I see you sparking in the dark/ (in day you just look wet and harried by the wind and I do not seem to know you)/

In the dark and the rain /the streetlight sparking off your leaves a bushfire/ trying to spread your wings with tiny birds of flame/ molten nails flying into the streaming rain/ a dog shaking itself dry of a shower of fire flies

yet the houses around are safe as

the children asleep within/ unaware of your fiery presence at their window/ and I no longer curse your presence in my land of akeake

we made the mistake 
of ownership

looked at this land

imagined how it was

when my tūpuna ruled

feltBetrayed

AbusedOutraged

that my British

kin had come

with progress

and laid waste

something changed

in my mind

I see land still the same

no man's hand

nor woman's womb

will alter whenua

beyond recognition

this land called women and men

brown and white across the sea

her karanga went forth

to carry our mothers

and fathers from

Hawaiki

Europe

Asia

Africa

The Americas

Oceania

this land

nurtured them with/

herRichDarkWet 
fertile folds and whenua

is still the same

as that one clothed

in mighty

kahikatea

rata

ti kouka

akeake

Forests of

pounamu

and still arriving
still claiming ownership still believing

we own her

Wendt

said

truth is.

she holds our bones

and our mothers'

and our fathers'

in herRichDarkWet

fertile folds and fields

forever and ever and ever

(Iain Strathern, “Akeake”)

John and Odessa were to have two sons during their marriage; my brother Mark in 1973 and me in 1978. Odessa and I had a prolonged stay in the hospital due to both of us having asthma and when she finally got home she declared that she would never end up in 
hospital again and from that moment on she battled her asthma attacks alone at home. John thought that she knew what she was doing, knew how to take care of herself, and so many times she did get herself through those attacks as if by shear will. The night of her last asthma attack seemed no different from the others. He had said that she should go to the hospital through the night and she had refused to go, until at last he rang for an ambulance anyway. It was nearly morning and the ambulance with its one officer arrived at the house in which my brother and I were still fast asleep; the house which held my entire life in every fibre of its mottled, brown and white 70s carpet, heavy floor-length orange curtains on steel curtain-rod and rings, and black and white baroque-patterned wallpaper. Every magical inch of that secure, stable, safe sanctuary was made possible by my father who built it, and my mother who loved me and held me in it. Dad was the provider, and we seldom had much time with him. Mum however, was always there - she was my very existence as a four year old.

Odessa never returned to that house, where small faces peered out at me from woodgrain, and marble-patterned tiles, where Peter Pan and Wendy smiled on me from my bedroom wall paper, as I slept under my vintage car bedcover, oblivious to the life-changing days ahead. My dad recalled to me the moment when she spoke to him with her last whisper of breath. He called to the driver to go faster as she stopped breathing. When they got to the hospital where they had first met it was already too late, she had been without oxygen for too long. She was resuscitated but never regained consciousness. Odessa died after about 8 weeks on life support when my father asked them to "do something" and the intravenous feeding was stopped.

Finding meaning is an essential part of living a happy life. All people spend their lives looking for meaning, whether it be through the study of physics, through religion, astrology or creating art. The search for meaning is the biggest question in human history. The question is there even when we fail to recognise that we are asking it. Stories are one particular way that human beings answer this question. If someone were to ask me who I am and what my life is about I would probably tell the story above. It is a story that holds a lot of information about me; my people, my places, my images; the story gives meaning to me as an individual human being. Without such stories a person is a face amongst the crowd, often faceless within the crowd. Though finding meaning in life is important to human beings in a general and universal sense, it is of particular importance at certain stages in an individual's life. Births, coming of age, marriage, becoming old, and dying are life stages which may be very stressful and traumatic and it is these times of our lives which may challenge our belief systems, our values and the basic framework around which we ourselves take shape. Obviously if this 
framework is damaged or destroyed a new set of values and meanings needs to be established, a person must rebuild themselves. Establishing meaning is one of the four essential steps of healthy grieving in children (Corr et al.). The other three priorities identified are: commemoration activities, expression of emotional responses, and learning to carry on with life and loving. The value of stories in this process of finding meaning is that we may choose which stories we tell, how we tell them and how they end. Thus creating values and meaning around a set of stories that is life affirming regardless of whether they are 'happy' or 'sad'. Such a treatment of our stories may help us move towards "healthy mourning [that] integrates losses in ways that shake off unhealthy obstacles and facilitate ongoing living" (15).

The creation stories used by King provide a useful example of how the stories we tell inform our values, meaning and self-images. Genesis may help us see ourselves as dishonest sinners, unworthy of God. Some may take the perspective that humanity is about toil and redemption. The story of the woman who fell from the sky is one in which we may see ourselves as playful, innocent and creative. Both are stories about the one event-Creation. As Thomas King points out, once we have heard a story it becomes our own and we can do with it whatever we choose, we can reuse it, we can change it to suit ourselves, or we can forget it. Like stories, we can do what we like with events in our lives $(29,167)$. We can make of these events whatever we like and even when we do not realise what we are doing, we are doing just that. We attach meaning to events. They become something to our lives and our sense of ourselves.

The story I told above is my own creation story. It is one, which I tell over and over again. It is the one by which all events in my life are measured and the one to which all events are anchored. My creation story happens to be one where death features most prominently so that when my birthday comes each year it is also accompanied by death. To know that this is common for people who lost a parent during their childhood allows me to accept this part of myself more easily than I did in past years. Below is an excerpt from something I wrote some years ago on my birthday.

Everything seems connected to that moment [of Mum's death]. I don't like to hear myself say it. I am scared that I am just being a poor me when I say that, but even just writing that now I can see that it doesn't have to be so. Everything can be connected to that moment but it does not mean that that moment must RULE my entire life. It may inform my life and everything in it but it may do so in a 
positive way.

One particular way to achieve this may be to actively seek meaning in everyday life. Mary Symes' Grief and Dreams takes a Jungian perspective on recreating meaning in one's life during bereavement through taking careful notice of one's dreams and interpreting the symbolic images into readable messages. It occurs to me that regardless of whether dreams are subconscious information, or messages from a spirit world or just brain-babble, by focusing on them we are able to interpret them into something meaningful to our own lives. This also applies to what happens in our daily lives, if we focus on meaning coming to us through the events of our day we will find meaning there. When we believe everything to be meaningless and hopeless then that is what we find.

This is another common experience for those bereaved of a parent in childhood; the feeling of constant emptiness, loneliness and the need to rethink throughout our lives who that parent would have been if they were still alive. This must inevitably make it difficult to look towards meaning rather than meaninglessness. My own life has been a constant struggle between these two opposites.

\section{Whaea,}

\section{tōku whetu}

What would you be now,

Shining star on my horizon?

Waiting for me at my setting

My zenith is still approaching

It's been such a long day already

Most of my mourning has been spent

Dreaming of a final eclipse, the death of a son

I have been longing to join you there at the edge of existence 
Had hoped that you would conspire with the stars and planets to make it so I have been calling out - e Whaea why hast thou forsaken me - there comes no answer (Iain Strathern)

Thinking creatively about the effects of colonisation and the skins it has helped to cover us in can aid the post-colonial healing process. In her paper on "Purakau as Therapy", presented at the National Māori Graduates of Psychology Symposium in 2002, Lisa Cherrington asserts that there is a therapeutic role that is played by pūrākau. When we think of this in terms of colonisation one of the most obvious places to start maybe with stories of Patupaiarehe or perhaps even more pertinent, Ponāturi. The stories of these white skinned 'fairy' people are demarcated by some notable thematic conventions. These are beings with powerful magic or technology who are seldom seen, they eat only raw food-finding cooked food repugnant, they kidnap Māori women or lure them to their own whare by use of (often musical) magic, and they are sensitive to light, making them active before dawn, at dusk, through the night, or on misty days when the light is dull. One aspect of these stories that I wish to explore in more detail here is that Maori tend to be the beneficiaries of Patupaiarehe knowledge or help. Yet they are considered dangerous and to be avoided at all costs. Also known as Pakepakehā, it seems likely that Māori associated Europeans (Pākehā) with the white fairy people. Why then did Māori embrace the coming of the white-men (albeit tentatively)? The simplest explanation is that Māori recognised the significant differences between Europeans and Pakepakehā and that the association was merely superficial. One of the main differences must have been that Europeans approached Māori in tentative peace, offering their technology as gifts and objects of trade. Also, they did not succumb to the light, nor did they actually live in the sea but upon it, or across it.

This part of the chapter explores the incorporation of Pacific myths of pale skinned beings into Patricia Grace's Baby No-eyes and Albert Wendt's The Adventures of Vela as a way of thinking creatively about the psychological effects of colonization. The idea that the self needs the Other in order to define itself is an old one and much discussed in a wide range of disciplines. In contemporary literature white-skinned beings such as Ponāturi come to represent the cultural and psychological effects of the coming of European culture to Polynesia.

Kōrero tara, have a long tradition of being used as teaching tools, as ways of knowing and understanding the world and ourselves as human beings. Discussing mythology in 
regards to Jungian psychoanalysis Robert Johnson made the statement:

Myths are a special kind of literature not written or created by a single individual, but produced by the imagination and experience of an entire age and culture and can be seen as the distillation of the dreams and experiences of a whole culture. They seem to develop gradually as certain motifs emerge, are elaborated, and finally rounded out as people tell and retell stories that catch and hold their interest. Thus themes that are accurate and universal are kept alive, while those elements peculiar to single individuals or a particular era drop away.... The details of the story may be unverifiable or even fantastic, but actually a myth is profoundly ... true.

Being "profoundly true" in this sense is a concept central to literary studies and to human enjoyment of stories in general. While a physiological account of the mastication of plant or animal matter, and the resultant gastric changes, and the journey of the matter through the digestive tract, may be an accurate representation of eating, it gives no sense of the human experience: the aromas, texture, and flavour, the hunger and anticipation, and the feeling of complete satisfaction at the end of a long awaited meal. This kind of truth is something that creative literature can provide. Furthermore, if we consider myths as reflections or records of the psyche of a particular culture, the 'truth' of such stories holds profound potential indeed. Cherrington points out "the use of purakau ... as a therapeutic medium is not a new process for Māori". She writes, "traditionally, purakau have been handed down from generation to generation to provide advice and insights to the thoughts, actions, and feelings of our ancestors" (117). Cherrington's work bringing pūrākau into clinical psychology can be seen to be part of a wider trend towards the decolonisation of research methodologies. As discussed by Linda Tuhiwai Smith, in decolonising methodologies the aims are "the survival of peoples, cultures and languages; the struggle to become self-determining, the need to take back control of our destinies" by re-centring indigenous ways of knowing. Smith asserts that Indigenous researchers must replace European methodologies with indigenous ontological and epistemological constructs in order to achieve academic autonomy from the imperialist and colonialist ideas inherent in Western research methodologies (Smith 142). Pūrākau / kōrero tara, are examples of ways of knowing that are emerging, or perhaps re-emerging is more accurate, as broadly adaptive methodological tools. 


\section{A Māori way of seeing}

In reading Māori texts which make use of kōrero tara, it seems obvious to make use of pūrākau as a methodological tool. Just as Robert Johnson makes use of mythology to read into an individual psyche, Māori literary studies can utilise kōrero tara to interpret contemporary narratives and draw out connections to contemporary society. Patricia Grace's Baby No-Eyes (1998) utilises kōrero tara in telling a story inspired by tragic real-life events. In the novel, a young woman named Te Paania miscarries when her partner Shane causes a car accident which kills him and critically injures her. The body of the baby is discarded into a Wastecare bin by the hospital. At the request of Te Paania's whanau, the baby is recovered so that she can be taken home for burial; however, before she is released to them the doctor tells them that he must perform an autopsy. When the baby is brought to them at last, her eyes are missing. The doctor retrieves them bringing them to the family in a container inside a supermarket shopping bag, an act that adds injury to insult by making Baby into a kai, a food. The act is analogous to eating the eyes of an enemy in order to take his mana. There is no explanation from the hospital as to why the eyes were removed in the autopsy or why they were kept.

The story of the events leading up to and following this central incident is retold by Te Paania, her Nan Kura, and her second child Tawera. There are other chapters told by a narrator in the third-person which are all focalised through Te Paania's friend Mahaki. According to Te Paania each perspective is essential to the telling of the story. "Gran Kura and me, and all of us in our different ways. You too", she tells Tawera, "you'll have to do your part. It could take years" (19). They weave together their individual strands of the story that link several older generations and the narrators, so that the reader attains a sense of how colonisation has effected the people of this family line and how the effects continue into present and future generations. The novel links to the future through the childhood relationship of Tawera and his spirit sister, Baby No-eyes. Tawera becomes his sister's eyes for her, explaining everything he sees, narrating the world to her, providing her life experiences and opportunities for learning and growing.

One of his major accomplishments as her constant companion is how he finds a role in his school play for his sister who only he can see and hear. Her role must of course be equal to his own: the legendary Tāwhaki, avenger of his father and rescuer of his mother. The answer is Tāwhaki Seen and Tāwhaki Unseen as for part of the story Tāwhaki becomes invisible in order to sneak into the whare of the Ponāturi a white-skinned sea-fairy people who killed his father and enslaved his mother as their door-keeper. They call her the Door, Te 
Tatau, and her job is to warn them of the approach of dawn so that they can flee from the sunlight into the safety of the sea. The rescue and revenge is achieved by Tāwhaki and his mother sealing all gaps in the whare walls so that no light can be seen from within. The Ponāturi oversleep and are killed by the rays of the sun when the doors are thrown open by Tāwhaki. Grace's re-enactment of Tāwhiki's deeds in the school play creates a new version of this pūrākau of which there is already many variants. Grace's school play seems to be based on the version of the story in which Tâwhaki is accompanied by his brother Karihi who helps to destroy the Ponāturi. Grace's version, though, has two Tāwhaki: a brother, and a sister with no eyes. Karihi also features in another of Tāwhaki's adventures in which they need to climb a vine into heaven. Karihi begins climbing but has chosen the wrong vine and falls to his death. The grieving Tāwhaki removes his brother's eyes and plants one of them which grows into the Hinnau tree, the seeds of which are known as karihi. The other eye he takes with him into the heavens where he comes to the abode of the blind, giant Whaititiri. Whaititiri, the goddess of thunder, is related to Tāwhaki so as he is about to be caught and sacrificed by Whaititiri, Tāwhaki shoves his brother's eye into one of her eye-sockets and the giant immediately sees that he is whānaunga and spares him. Tāwhaki stays with Whaititiri for a time and gains much knowledge from her, which he later shares with humanity on his return to earth. Wisdom and growth are common themes in stories of confrontation with the white skinned fairy peoples and Grace brings this to life in a contemporary story which links the real world to the world of stories, the present to the past and future.

The struggle against domination by the white-skinned beings in the story of Tāwhaki, like the struggle of Te Paania's whānau while painful and tragic also holds a great gift. Such gifts often arrive in response to being stretched to the limit. Te Paania is stretched to the limits of life itself, but she pulls herself back into the world of light, paving the way for her to be stretched more and more on her journey back to wholeness. The medical establishment stretches her as does her work on Mahaki's campaign for the return of sacred land. In this secondary storyline, the white-skinned Other is represented by the council who refuses to return land to Mahaki's people. Like the medical establishment that violated Baby No-eyes, the council does not act according to the same ways and values as Māori. Like the Ponāturi, both of these Pākehā institutions have powers that are difficult to overcome. As with Tāwhaki the answer is ingenuity through seeing things from a new perspective. With the land claim one of the difficulties that is faced is that the land they want returned is unused and remote meaning that an occupation of the land itself would probably draw little attention. This would allow the council to ignore it as it had done for many years when the issue was raised by the 
tāngata whenua. The innovation comes from Te Paania, who suggests to Mahaki that they move the cause out of the margins and back into the centre by occupying a public park outside the council buildings, drawing attention to the claim and forcing the council to act (150-177).

Such recentring of indigenous concerns and ways of seeing are at the heart of Smith's Decolonising Methodologies, and the works of other indigenous academics such as Konai Helu Thaman, Epeli Hau'ofa, and Vilsoni Hereniko. Part of the decolonisation of Māori and Pacific knowledge is to challenge the accepted categories. Testing the boundaries between Māori and Pacific Islander in particular is one of the most significant and exciting challenges facing Māori Studies at present. Alice Te Punga-Somerville's Once Were Pacific examines the borderlands drawing insights from literary texts and creative works in other media. Te Punga- Somerville points out danger for Māori in reasserting their connections to Oceania, in that we, as tāngata whenua, claim rights to the land of Aotearoa by indigeneity and that by emphasising migration traditions from Oceania and cultural and linguistic connections to other Oceanian peoples we leave ourselves vulnerable to the argument that we are just earlier immigrants and therefore have no more a special relationship with Aotearoa than any other group of immigrants. Such arguments fail to take into account the British recognition of Māori sovereignty prior to the Treaty of Waitangi as confirmation of Māori rights in this regards. However, as we as Maori move away colonial ways of understanding our place in the world, we are faced with the question of which direction to turn. As we continue to divert our sights from Britain, we may find ourselves brown-skinned but wearing whitemasks, to paraphrase Franz Fanon (1986). Māori have seen their relationship to Pacific Islanders through colonised eyes, often pitting former against the latter. Our ancestors revered those ancestors of ours who made the journey to Aotearoa from their homelands. This suggests an obvious relationship with Oceanian ways of knowing, that is already supported by ancestral knowledge systems such as tātai and kōrero tara. These knowledge systems actually prescribe that we make such connections. Māui myths around the region, connect us as the ocean connects our shores. Our peoples connect through tātai.

Returning Pacific culture to the centre of our ways of knowing the world as Oceanians is one of the major themes of Albert Wendt's The Adventures of Vela. These epic chronicles of the deeds of Nafanua, goddess, warrior, uniter and peacemaker of the Samoan islands, stretch from pre-contact times into the present, culminating in a revision of world history and the identity of its Grand Architect. Wendt approaches the subject of decolonisation and recentring Oceania as our seat of knowledge, not by trying to erase European influence from 
the Oceanian slate but by subsuming it: making it ours, and making it all part of a great Sāmoa-centric plan. In a prelude to the coming of Europeans to Sāmoa chapter 13, 'Grave by the Sea', reveals Nafanua's story of Maifea? a white-skinned man washed up on shore one night who Nafanua adopts as her son. Nafanua and her taulaaitu, Auva'a, see that Maifea? is from a world beyond their knowing, perhaps even beyond the knowing of the apparently omniscient Tagaloaalagi, thus the name Maifea? meaning From where? Maifea? is explained to Nafanua's followers as the "Sacred Albino gifted to Our Lady [Nafanua] ... to show us what unconditional love is" (103) but it is clear that this is no albino. The reader recognises him as European from Nafanua's description of his attire - "a loose blue skin with a line of silver shells down the front/ Feet encased in hard black skin" (99). Nafanua also recognises that Maifea? is a man "not a beast" (101) and not a supernatural being. She sees that he comes from "a world with technology magic/ and mana" (100-101) Realising that the knowledge he represents is very powerful, she determines to keep him and it to herself. Unfortunately Maifea? is no great sage, in fact he is of no use at all. He has lost his memory, not to mention every scrap of social etiquette, so he becomes more of a pet. Actually, less than a pet as he simply cannot be trained even to the most basic level. In spite of this, perhaps even in light of it, Nafanua, the great warrior goddess, comes to love him unconditionally and she risks everything for him in open war with Tagaloaalagi. Nafanua had approached the creator god to see if he could return Maifea's? memory to him. She describes Tagaloa's reaction to finding that he is unable to "unleash Maifea's? mind/ and acquire the secrets of his world"-

$$
\begin{aligned}
& \text { Tagaloa was now afraid and humiliated } \\
& \text { to learn there were other atua with greater } \\
& \text { mana in worlds outside our comprehension } \\
& \text { who could like Maifea? burst through } \\
& \text { our horizons and convert our people } \\
& \text { to their gospels and we could die }
\end{aligned}
$$

A series of assassination attempts ordered by Tagaloa fail and Nafanua humiliates Tagaloa's chief assassin, precipitating a declaration of war by Tagaloa. During the action that ensues Maifea? who is in hiding with Nafanua's people is killed by the goddess's own taulaaitu, Auva'a, in order to protect Nafanua and her religion. Maifea?, the teacher of unconditional love, sacrificed, the chapter ends with Nafanua finishing her narrative to Vela and the two of them awaiting, the arrival of "Maifea's? Miracle-making kind/ on the next full tide to wake 
him/ from his grave" (118). Such white-skinned beings with blue eyes were, as Auva'a exclaims, "pro-/ phesied [as] foreign atua" in pre-colonial Sāmoa (101). Atua here does not necessarily mean gods as it is usually translated, but covers the spectrum of supernatural entities. But Wendt is certainly pushing "mindless Albino" (104) Maifea? into the realm of the divine, as some might say the historical Jesus has been since the time of his execution.

The potential for unconditional love comes with Maifea? but the fear of the unknown conquers it. Like the story of Christ coming to teach unconditional love and being killed for it; and the story of missionary Christianity, coming with the intention of spreading Jesus' love but instead spreading disease, guns and cultural death — creating a breeding ground for 'vampires' as Wendt calls such human qualities as racism and greed. The "Grave by the Sea" may then speak to us of the death of the potential inherent in the coming together of European and Pacific cultures.

Ironically, Tagaloaalgi does provide some insight into the meaning of Maifea? after all. On the declaration of war by Tagaloa, Nafanua, being the greatest warrior and strategist of the gods, hides her people and Maifea? and races to the abode of Tagaloaalagi, who is alone on account of having sent of his retinue and armies to kill Nafanua and wipe out her people and religion. The confrontation which ensues ends in Nafanua discovering Tagaloa's weakness, his love for his pet bird, Tulī. Nafanua catches the bird

I ran calling Tulī! Tulī! Tulī! In

perfect imitation of His bird

Being preening egoists Tulī can't resist

their own call—so down it flapped from

its hiding place...

As Nafanua grabs the bird and threatens to kill it she realises that Tuli has become invested with Tagaloa's ego, to kill this bird would be the death of Tagaloa, because of his love for it. He had projected himself into the bird and loved it as he loved himself.

It's only a useless bird! [Nafanua] echoed his judge-

ment of Maifea?...

Alright I won't harm Maifea? [Tagaloa] called 
Nafanua takes Tulī as hostage and messenger to Tagaloa's troops telling them to return home. Alas too late for Maifea? On discovering Maifea's? murder, Nafanua in her anger bites off Tuli's head and rips its body apart. In the aftermath of these events, Nafanua, suffering a nervous breakdown, is nursed back to health by Tagaloaalagi and when she revives he says "thank/ you for rescuing me from the sickness/ I'd become it's good to be rooted in earth and people again Both/ Maifea? And Tulī were useful in their uselessness" (117). Tulī, the "preening egoist" had become a mirror for the supreme Tagaloaalagi who feared for his supremacy. The whole world had he created in his own image and he had come to believe that that world was the only one there was; that His was the only reality. The death of Tuli makes him realise that there is more to the world than just him: there is "earth and people". He has experienced a rebirth, a renewal; he becomes grounded again, seeing the world from a new perspective. This healing, as he acknowledges it to be, is achieved through the death of the object of his love, the death of the self. Shaking the foundations of our realities to enables us to see anew. New ways of seeing the world allow us to overcome seemingly impossible obstacles.

I want to follow this thread of egoism for a while by moving, as the book itself does, to a later episode where Vela, in a sense, becomes Maifea? As Book Two "Chronicles of Nafanua" ends with the story of Maifea?, Book Three "Travel", begins with a possible response to the question From where? Chapter 14 is "Nei"-Here and Now. "Nei" opens with Vela fishing on the high seas, and for his greed being shipwrecked by a storm and awaking on an unfamiliar island, where he is, in relation to the people of that land, very paleskinned. "[I] woke to a hushed sky of blueblack faces/ and almost shat believing my captors Fijian/ the most ferocious maneaters in our region/ reshut my eyes hoping it was a dream but when/ I peered up again their sky was still/ /grinning in blueblack silence (123). In effect Vela comes to represent the coloniser, he is welcomed into their community even though it is a very structured and complete one with no need for anything from outside their world, and Vela turns their way of life upside-down. Essentially Vela abuses the generosity of the Tagata-Nei by manipulating them via their method of communication, which occurs within the communal mind. Wendt places the very harmonious and communal Tagata-Nei culture beside Samoan culture which in relation is very conflict ridden and individualistic. He also places in the hands of the paler-skinned immigrant the means by which to convert and control the Tagata-Nei. The use of a method of communication as the means of conversion and 
control satirises the bringing of alphabetic writing, in the form of the Bible, to Oceania by European missionaries, and the recognition of this by indigenous populations as a very useful technology holding "magic / and mana" (100-101). Missionary attitude in general was patriarchal, believing the indigene to be superstitious and uncivilised. Unable to recognise the sophistication of the host society and the danger he poses to it, Vela revels in his new found power to convert the Tagata-Nei to true, Samoan-style civilisation. He begins with the manner of pig-slaughter, "Clubing is so primitive so I introduced the civilised Samoan method of strangling e.g. / Pig upsidedown hard yoke pressed down / across the windpipe silent and bloodless / My crew hummed their approval(132).

"Nei" parodies Jonathan Swift's Travels into Several Remote Nations of the World (1726), more commonly known as Gulliver's Travels, or simply Travels, one of the most well-known satires in English literature. Wendt parodies Travels, just as Swift parodies the travel literature genre which enjoyed immense popularity in the $18^{\text {th }}$ century. Moreover, Wendt gives the reader a glimpse into how strange Europeans and Oceanians may have appeared to each other, and of course the farcical nature of one culture trying to fix another. From such attempts comes huge social chaos and on the individual level, in the face of two competing sets of social norms and expectations, comes shame. 


\section{SKELETONS}

In the loft of the house, under the rafters, looking at the old photos put there to be forgotten. By European standards it's incest. In certain circumstances in the Māori world however, it was acceptable for a woman to conceive a child for her sister by her sister's husband. "In certain circumstances". Yes — blood lines were everything to the old people so I am told. But they didn't live by the old ways then, dressed up in those fancy English clothes, and holding parasols. They might have worn the clothes but they didn't live completely by English custom either, not even the English did. So many prohibitions! Who could keep up with all that? But I don't know that it had that much to do with the old ways or the English ways. I think he was a bit of a bastard, and I don't mean born out of marriage! Though he probably was that too! Yehprobly! I heard it said that he would not let the sister leave. Her mother finally took her away to work on the stations out in the wups somewhere, Nan never knew who her father was, it was just never spoken about, not in front of her anyway. He was Māori, nē? Ae. He was Pākehā, wasn't he? Yes.

\section{(Iain Strathern, "Shush/Turituri”)}

The object of this chapter is to explore the complexities of negative and often hidden stories that contribute to the construction of post-colonial Māori / Oceanian identity. These stories are of experiences that scar family histories - the ones your mother would stare you down for attempting to bring up, or she'd brush over and change the subject; more often they're ones that you'd never bring up because you don't even know they exist. With the sketch/poem above I have attempted to express how colonisation has contributed to such skeletons by blurring the boundaries between what is acceptable and what is not. It also hopes to represent the ambiguity of past events, and the 'truths' that are passed on through story and the 'truths' that may be lost through silence. Most of all I wanted to depict a matter-of-fact 'conversation', unemotional in tone, that might occur between two family members, whānaunga, or could just as easily be a conversation happening in side one's own head. This is the foreground-leaving the family shame in the background with the title and the opening 
line. This kind of shame is passed down through generations even when the story goes untold. Kids know when their parents are lying, when they're hiding something, when they're are ashamed of something. The unwillingness to tell the stories compounds the trauma, making it abstract, ambiguous, something hiding in the closet.

These 'skeletons' of our personal and familial psyches inhibit Oceania's healing process because when we are unable to voice such stories, making them tangible in a sense, we are unable to examine where such events might have come from. In everyday living we often underestimate the significance of colonisation and therefore underestimate the value of decolonising. What decolonisation means in real terms, in real lives is the subject of this chapter. Following a more indepth discussion of the genealogy and nature of our 'skeletons', the chapter shows Wendt's playful intertextuality providing a recitation of a particular line of descent.

Complex, real-life social issues, however, can be a bit confronting. People get their backs up. It can get pretty ugly. So, witty people around the world have utilised methods of social critique in comedic forms. Samoan faleaitu, is a form of theatre providing an outlet for criticism of community leaders through comic sketches (Maufort and O'Donnell, 309). The Adventure's of Vela uses the tradition of faleaitu, while also mimicking the European tradition of satire. Vela's sojourn in Olfact, the other South Pacific island treated by Alapati, displays elements of faleaitu in written form. Furthermore, the similarities between Gulliver's and Vela's travels which are at once apparent even to readers who have never picked up Gulliver's text, create a rich dynamic somewhere between faleaitu and English satire, that points out the universality of issues of conformity and innovation in world cultures, as well as the different attitudes to dealing with such issues.

Following discussion of Olfact, the chapter moves further into the depths of the intertextual warren built by Wendt with a short exploration of the episodes regarding Mulialofa, Vela's first love who after losing a composition challenge is stripped of his mana, and his skeletal structure by the winner. The still living Mulialofa, though he begs to be left to "dissolve to earth" (27), is taken by Vela into the hills where, out of pig bones, Vela fashions a new skeleton in an unprecedented experiment that may be the first-ever vivisection. The subject of vivisection will be discussed in regards to H.G. Wells' The Island of Doctor Moreau and the Victorian vivisection controversy, which will eventually bring the chapter back to Baby No-eyes where the physical removal of Baby's eyes takes on multiple nuanced layers over the course of the book. Ultimately, Baby's story demands of the reader a new way of seeing the world. 


\section{Bedtime Skeletons - a Genealogy}

'Skeletons' is the term my Grandfather, Jackie, used to use when he'd had trouble getting to sleep. He'd joke about it the next morning. I can here his sing-song voice, the Scots accent still broad, "Y're lyin' there and the skeletons start tae come out of the closet", and I think he'd do a little skeleton move along with those words, he was always such a physical and expressive storyteller. Then he'd pull the invisible sheets in around his neck, close his eyes tight and burrow his head into the imagined pillow trying to block them out. But it didn't matter how he tossed and turned, those skeletons had him in their grip. Until finally in the darkest hours he'd go to the kitchen and have a bowl of cornflakes to at least quieten the beasts in his stomach. I don't know what his skeletons were. Grandad hadn't known his father though, because he'd died soon after Grandad was born. He never talked much about it but always seemed as ease with the fact; I don't know if this was one of the things he thought about on those nights, but I knew a lot of his other stories-I knew him pretty well.

The skeletons of this thesis may very well be quite different to the ones that kept Grandad awake some nights, or they may be similar. The annexation of Scotland had occurred over two and a half centuries earlier and full union over 200 years before Grandad's birth, and he harboured few, if any, grudges against the English. Indeed, he believed the Scots were better off being British than they would have been independently, besides which, his gripe was against rich capitalists and industrialists who used the working-class to satisfy their "greed for gold". English domination was for him an outdated way of looking at the situation, and there are many reasons why his communist perspective may have been more appropriate for the Scottish situation.

When Jackie and Cathie moved to New Zealand in the late 1960s, the capitalists and the communists were still at war with one another but all that was in Other parts of the world, not here in God's own country, a class-less society and racially harmonious paradise. And yet Hone Tuwhare still wrote the poem "Speak to Me Brother" (116-7), humorously depicting a brown, working-class, brother against brother scenario in Aotearoa that questions our complicity as Māori in conflicts in those Other parts of the world. The justification for taking part in such conflicts comes straight from the mouths of the American propagandists, Grandad would have said. In the case of Tuwhare's poem, it was the Vietnam War, and the job of the propagandists was becoming more and more difficult given the vocal opposition to the war. "Speak to Me Brother", adds a specifically Māori tone to the protest, pointing out the 
farcical nature of fighting for freedom against people half a world away while being dominated at home.

Is that right.

You don't want them to dominate us?

Like, they're going to paddle down here on

the wooden sanpans, eat all our pork-bones

and puha: fork out ninety cents for a

muttonbird

Moreover, the poem speaks to the fighting of Māori towards the domination of a people in their own country by an invading Anglo-centric culture claiming to be motivated by humanitarian concerns and to have all the answers.

Hell, you think those farmers are sick of growing rice?

Look here, those rice farmers have got a big feeling for their own land: their own food: their own gods. Listen:

(sing) Planting rice is not much fun if you have to carry a gun, When them come down out of the blue then you have to plant then too

Skeletons of the Vietnam War are probably still keeping some old men awake at nights, and old women, and the not so old too. Maybe some of those lying awake are Māori, Aboriginal, North American Indian, Hawai'ian, Samoan even. However, there are some skeletons which are too much to live with let alone sleep with, especially when we don't even know why we have them. Sam Ybarra was a US soldier in Vietnam who came back to the San Carlos Indian Reservation, where he was born in Arizona, where he lived with his 
Apache mother until he died at the age of 37 of pneumonia. Reportedly, he was depressed due to his actions in the war (Sallah and Weiss 270-1, 336). He had good reason to be; he was part of a special force-Tiger Force - that was responsible for some of the worst atrocities of the war, and he was apparently one of the worst offenders in the force. Did he know about the animosity of US army soldiers against Apache peoples in the 1870s? Did he know about how many Yavapai-Apache men, women and children died on the forced march to the reservation in 1875? Maybe he did, and maybe he took his anger out on those he was paid "good money to blast ... out of the bush" (Tuwhare 117), or perhaps he didn't know the whole story, maybe he had no idea why he had so much anger inside.

\section{Stiff upper-conformity}

It seems then that all our skeletons may be related somewhere down the line, so should it be so hard to talk about those painful moments? Perhaps we just don't want to relive that pain, especially not in front of our children. Shouldn't let them see us vulnerable after all. Skeletons we don't even know exist hold such power over us. However, they hold great potential for individuals, families and communities who choose to dust them off and bring them out into the world of light. Of course the courage to do so can be difficult to summon. Shame makes it a challenge.

Some desires lead individuals into shame; they are the ones that are socially unacceptable. They are not the same in all cultures, and not all cultural groups deal with indiscretions in the same ways. Colonisation with its inherent issues of superiority / inferiority, adds to the complex nature of such situations by unbalancing the social equilibrium. When an external culture succeeds in dominating the original community, people of that community are under the pressure of two different and often contradictory social expectations. In lands such as Aotearoa, where two differing value systems have been in contact for a short two hundred year period, one culture's norms have become and remain dominant, often at the expense of the other. Social norms have always had some dissenters, even if unvoiced and submissive. In Aotearoa social critique takes many forms, from overt political activities, such as the 1975 land march, to the BATS theatre production of Miria George's And What Remains. Albert Wendt has been a critic of New Zealand society and the wider Oceanian region since the 1960s. So it comes as no surprise that he would dedicate The Adventure's of Vela to the memory of two of the other great Oceanian social critics, both of whom died shortly before the publication of the book, Epeli Hau'ofa and Hone Tuwhare. Like Tuwhare, Wendt employs humour to make some very serious points. 


\title{
Swift meets Faleaitu - a line of descent
}

Jonathan Swift also wrote in this tradition, and Wendt honours this lineage with the chapters on Nei and Olfact. Probably the most obviously co-incident motif, however, occurs outside these chapters. It is the curse of immortality without eternal youth, from which Vela suffers, as did/do the Struldbrugs of Luggnagg in Gulliver's Travels. Such usage of material from Western popular culture, may be read simply as humourous kitsch references, as one might when Nafanua, the ancient goddess of war, sings

\author{
He loves you yes yes yes \\ He loves you yes yes yes \\ He loves you yes yes yes! (61)
}

Yet a closer reading that takes into account the many varied references, reveals what seem to be a number of plagarisms. If Vela and Nafanua are the original composers of the texts, as Alapati informs us they are, the logical conclusion is plagarism committed by Swift, the Beatles, and Wendt himself (Vela is recorded as the composer of "All Streets Lead" an almost identical text to the poem published by Wendt twenty-five years earlier). Of course such plagarism is difficult to prove, given the later publication of Vela and Nafanua's compositions as part of Wendt's record of events. However, the overall effect by the end of the novel, if not before then, is the sense that Nafanua, with the mighty efforts of Vela, has influenced Western culture, to an extent that the West could well feel that it has been colonised. Could this be why Swift's protagonist has such a Sāmoan sounding name, a backward English transliteration of Vela perhaps?

Swift's Laputa, the ultra rational nation, who float high above the rest of the world condemning the lower races of humanity by throwing rocks at them, holds a similar cultural trait to Vela's second port of call, Olfact. In Laputa, science has become an end in itself, meaning that it is used for totally impractical purposes. One use however, is to discover political intrigues. Unfortunately, it is accomplish through the dirty business of faecal examination (92; pt. 3, ch. 5). Olfact's science is of course the science of smell, and crime may also be solved by attention to ablutions. For instance, Vela reports witnessing Olfact's "famous detective Manogimoenofo" discovering the identity of a killer by the scent of his urine (160). 
Such 'animalistic' qualities of the Olfactors, is one of the major motifs apparent in the chapter on Olfact. To the Olfactors, this ability is a sign of civilisation and superiority, thus, Vela is tolerated but considered primitive due to his being "smellectually" deficient (170).

Sensitivity of olfaction is measure of ability

Even art so in their terms we're

Primitives not far removed from the odourless beast (159)

The comedy of Manogimoenofo, chasing off "into the breeze"(160) after a killer, the odorous smellsongs with smellsounds beyond the range of non-Olfact-human hearing (167), and the traditional Olfact greeting, which has the added exchange of genital odour as well as the more common Polynesian exchange of breath are evocative of canine culture. The reader might, therefore, be encouraged to make further connections with Lemuel Gulliver and his travels, especially his sojourn in Hoyhnmnland, the land of the horses. In this land, Gulliver is also seen as inferior and, like Vela, acknowledges himself to be so. This acquiescence places both characters in the position of 'underdog' and allows the reader to sympathise with him and critique the 'superior' culture that is represented. Of course, the representation of that culture is fantastic and absurd, and at the same time so very similar to the contemporary societies we live in - providing distance from one's own culture and new perspectives on it.

Gulliver attains a new perspective on his own culture and species by his stay in Houyhnhnmland. In this land he is at first unable to distinguish between the civilised and the beastly as it is the horses that rule here and the human beings, known as Yahoos, are their primitive beasts of burden. The Houyhnhnm accept Vela as an interesting oddity not only because he is able to converse and act in a civilised manner, but also because his 'skin' is different to that of the other Yahoos who go about naked. However, when a Yahoo woman becomes wildly aroused by the sight of him bathing naked in a river this breaks down one of the psychological barriers between Gulliver and the beastly Yahoos.

This was a matter of diversion to my master and his family, as well as of mortification to myself. For now I could no longer deny that I was a real YAHOO in every limb and feature, since the females had a natural propensity to me, as one of their own species. (134; pt. 4, ch. 8 ) 
Gulliver is so ashamed of his species that on his return to wife and children he is repulsed by them.

When I began to consider that, by copulating with one of the YAHOO species I had become a parent of more, it struck me with the utmost shame, confusion, and horror. (149; pt. 4, ch. 11)

Gulliver becomes a victim of another culture's social norms and cannot rid himself of their condemnation. He has accepted the 'truth' of humanity's inferiority, as many colonised peoples accepted their place within the hierarchy of an Anglo-centric empire, the psychological impact of which is still causing "shame, confusion, and [even] horror".

Animal, Vela, or mineral?

In Olfact, Vela is faced with shame also - not his own, but the shame of his Olfactor lover, Manogilaumaile; "how could she desire the essences / of a primitive who was smellectually handicapped?" (170). Vela's sexual and romantic involvement with Manogilaumaile are described in section “(6) Love and Courtship" (169-175) of a detailed anthropological treatise. In this form, the chapter on Olfact places itself along side works by scholars who have observed Oceanian cultures. The most notable of whom, in the Samoan context at least, is the anthropologist, Margaret Mead, whose erroneous findings in regards to Sāmoan sexual culture have become legend. Traditional Olfact love-making is a hands-off activity, involving only the sense of smell, but Vela after becoming well schooled at "lovesmelling" begins to introduce to Manogilaumaile "our way of loving: / a finger touch here", or "a lingering caress" at a time, until the pair have melded the two sexual cultures together. "And what a combination!" it is according to Vela (174). Unfortunately, theirs is a forbidden love; Vela goes on to tell of Manogilaumaile's shame at the thought of revealing their relationship to others and their eventual discovery by her family.

The following trial leads to Vela being 'declared ... smellectually a beast', his consequent expulsion from their country, and Manogilaumaile's sentence of Smellwashing for the crime of bestiality. His expulsion also links him to Mead through Wendt's earlier character Professor M. Freemeade in The Mango's Kiss. Freemeade's sexual liasons with some village youths leads to his expulsion from Satoa and being banned from visiting other villages. The episode dramatises the power dimensions of Anglo-American ways of seeing 
the world attempting to dominate the indigene by claiming a monopoly on 'objective truth'. Claims to objectivity and truth, have often been used to subdue challenges to authority. In Olfact, Manogilaumaile, accepted the judgement handed down upon her:

she was repentance

and vulnerability - the patient pleading

to be cured .... a willing victim

of a system which had determined that

she obey even if it demanded her death (180)

That sexual deviance from the prescribed social conventions is a 'sin' in Olfact will remind readers of puritanical Christianty's notion of the sinful flesh. This parallel is reinforced by Vela's description of

\author{
Manogitupusili ... \\ Who incidentally is chosen by the Smellocracy \\ out of its own ranks (in a similar fashion to \\ the College of Cardinals choosing the Pope) (176)
}

and his mention that Olfact's

\title{
Senior Olfactoroligist Manogi- \\ lotoalofa Smell-of-Loving-Spirit
}

[is] famous for his love of children and developing

the science of Smellwashing to save sinners (179)

Such satirical treatment of some serious social issues (power, justice, intellectual and sexual freedom) follows the tradition of faleaitu the theatrical Samaon tradition which allows comedic critique of community leadership. Wendt writes a 'performance' that makes fun of and points out the serious implications of human understandings of superiority and inferiority in regards to culture, physical ability, class and status, gender, and sexuality. By juxaposing recognisable current cultural traits, with Olfact's seemingly absurd smell-centric traditions Wendt draws the reader into a discussion on the dynamics between social power and the 
ability of human societies to move beyond old ways that may no longer serve the community while not succumbing to the fate of the Tagata-Nei, loss of cultural identity.

To readers Manogilaumaile's trial and the sentence of smellwashing might seem analogous to witch trials and inquisitions. The intolerance of deviance from the social norm may represented by such activities, can be seen in less well-known programmes such as the US eugenics programmes that began in the early twentieth century and ran, in various forms, for nearly three-quarters of that century and helped to inspire Nazi eugenics (Kuhl). Marginalised social groups such as the poor, the non-white, and the intellectually disabled were targeted for sterilisation. The victims were mostly women (Ward, 95). The most recently targeted group for sterilisation was Native American women, this continued up until the 1970s. Smellwashing, Olfact's ultimate 'scientific' mechanism of conformity, might remind us of sterilisation due to a similar terminology. Euphemisms such as racial purity, ethnic cleansing and racial hygiene are terms that have been used to 'sanitise' a dirty science.

Another scientific activity that shares the same lineage as eugenics is vivisection and the connections between the two in regards to the conflation of animal and human bodies are striking. Such failure to effectively discriminate between animal bodies and the bodies of disadvantaged individuals, such as the poor, the non-white and the intellectually disabled, is extraordinarily relevant to the social theories of the colonial era and therefore relevant to indigenous healing as such theory has been passed down the generations and has contributed to Māori and Oceanian identities in often very insidious ways. Sterilisation of Māori is the subject of Miria George's And what remains and has been a recurrent topic of discussion for politicians since the advent of eugenics, and for popular talkback radio hosts ${ }^{1}$, since people started listening to them. That such blatant conflation of human bodies and animal bodies is still current in New Zealand society demonstrates the importance of decolonisation in this country.

Wendt's conflations of animal and human bodies in The Adventures of Vela are often very humourous, such as Vela's first adventures into sexual intercourse occurring in the pigpens and accompanied with one of his first ever compositions which he would forever after sing "under his breath whenever

1 For two recent examples see http://www.radionz.co.nz/news/national/132042/call-for-resignation-oversterilisation-remarks http://www.stuff.co.nz/sunday-star-times/columnists/7034691/Pay-them-sterilise-them-but-don-t-let-themhave-kids 
he thinged woman man or beast:

Pig is best

Pig is delicious

Pig is true aristocracy

Pig Pig Pig!

Pig never spits back

So hold still hold still my lovely hold still (16)

Such humour provides the background for Vela's first human love relationship with Mulialofa - "the abundant taulasea from Lona / (with his bundle of cures) // Mulialofa-Taulasea-o-Fatu Mulialofa-Healer-of-Hearts" (18) - an affair which ends in such tragedy that Vela is forever transformed. Sāmoa's most powerful talking chief, Alopese, challenges Mulialofa who is also a songmaker of great talent, to a battle of words which ends up lasting fourteen days. Alopese's victory allows him to "demand anything of the vanquished" Mulialofa (25).

'I demand his bones' Alopese said

with long bamboo knife they slit open

his right leg from groin to toes

He didn't utter a sound

peeled away the bandage of flesh

(The malae began to drink his blood) (26)

Though this excerpt bears striking similarity to a vivisection, this may not be the first thing to come to the mind of the reader, especially in light of what follows. Next, Alopese's supporters

Broke out the thigh bone

Tossed it to Alopese who whooped

sucked the marrow out noisily

and out of the hollow bone made a flute

He fluted arrogant tunes

While they unstitched each bone

from the house of Mulialofa's flesh 
and tied together with sinnet a Bone-man

white as smiling teeth who danced

one-legged to Alopese's fluting song (27)

Not really what we imagine of the vivisectionist at work. However, Vela's actions following this scene and the motivations that drive him, certainly strengthen the relevance of the vivisection connection. Motivated by the desire to heal Mulialofa, Vela lifts his boneless flesh and skin out of its "bed of blood" on the malae

and to the dreaming mountains carried

him like a bride

Trapped wild pigs and of their

bones and one skull built a new frame

for his flesh (27)

Though the operation is successful it is more than bone that needs to be replaced for Mulialofa to truly heal. Stripped of his mana, and ability to stand et cetera, Mulialofa had "begged" (27) to be left on the malae, but Vela does not comply and his grief instead dictates his behaviour in a scene reminiscent of Shelley's Frankenstein. In the morning when Vela awakes and finds Mulialofa gone he steps further into the role of Doctor as he searches the mountains. In this way, Frankenstein's story of desperation, in which, finding and destroying his creation "is the devouring and only passion of [his] soul" (172), becomes a desperate love story of Vela's search "In the unravelable maze of mountains" (28). Unlike Frankenstein in the Swiss Alps, Vela never finds his creation. Like the troubled Doctor, however, Vela is never fully able to lay Mulialofa to rest, even after he achieves his vengeance against Alopese in a scene reminiscent of a freestyle rap battle.

As an old man beginning his recollections of Mulialofa and the battles with Alopese he composes an introduction to the retelling:

The contest remains a divining bowl of seawater in my decaying skull (in it I read again the tides of my life) (23)

and at the story's end, he returns us again to the present with 
Tonight I catch again the homeless wailing

of the Pig-man in the sad mountains

of my soul

... I'm a long

remembering but have deciphered

little from that water cupped

in the desperate hands of my skull (32)

Reliving the demise of Mulialofa and his own triumph which thrusts him into a new life as the great tulafale to Tuimanu'a and later to Nafanua, Vela admits that he has "deciphered little" and the image of "the last rising sun" (33) that he conjures leaves the reader with the feeling that the memories still keep Vela awake at nights, even after hundreds of years.

Inevitably, history shatters all 'perfect' moments, just as Vela's perfect moment with Mulialofa was shattered. For lovers the sun must rise, as colonial empires must also; natural disasters strike peaceful fishing villages, and Alopeses come into our lives and challenge us to our cores. And of course we will never be the same again, we will forever carry those moments, those memories, those stories. The world still carries scars from history changing events and people, scars such as Social Darwinism, Eugenics and of course Vivisection. What do we do with these things that we must carry?

\section{Well it's all in the past isn't it. Lets just let Bygones be}

Susan Hamilton's "Still Lives" explores the conflation of human and animal bodies within the antivivisectionist movement of late $19^{\text {th }}$ century England. The movement was largely driven by female activists and in many antivivisection publications of the time women were called upon to work for the cause in ways befitting their social status. These ranged from signing petitions to social sanctions. Regarding such sanctions, Hamilton writes

It is this latter component of "women's work" in the antivivisection movement which is, I think, most interesting. Over and over again, women are exhorted not to consort with the vivisector, specifically not to marry with them. The price women pay for not heeding this advice is graphically indicated in the many stories published in movement periodicals about the horrors of the life of the physiologist's wife. These social sanctions were also 
extended to those many medical practitioners who were known to be supporters of vivisection. Women were directed to refuse attendance by such doctors. We could argue, of course, that such social sanctions constitute a displacement onto animal bodies and vivisection of anxieties concerning the efficacy and morality of emergent Victorian medical practices. But what is important here is to note the way in which such social sanctions worked to deny men associated with vivisection access to women's bodies, bodies which, as the identification with the vivisected animal body implicitly indicates, are already figured as potential subjects for the bloodied hands of the "working" physiologist. (31)

Hamilton continues making the connection between gender and class in relation to power and passivity, a connection which can easily be extended to other marginalised social groups.

The large amount of space that movement periodicals devoted to documenting what we might term interventionist medical practices - what they termed "human vivisection" indicates the degree to which human and animal bodies have been conflated in the antivivisection movement. Importantly, the cases of "human" vivisection most often described in antivivisectionist periodicals concerned women patients and working-class patients which the periodicals themselves "feminized" as passive, unresisting victims. It is this feminine, vulnerable, unresisting body which women sought to deny, to keep hidden from vivisection. (31)

To this "feminine, vulnerable, unresisting body" of marginalised nineteenth century humanity, we might easily add the indigene, and particularly the eroticised, exoticised Polynesian. In the Victorian era the differentiation between class and race, was less clear (Rich 16, 20-22); "the Cockney race" was used to refer to the London poor of the East End, and theories of racial sciences confirmed the inferiority of the Irish race, legitimising the inferior status of Irish migrants in England and as part of the Empire, to the extent that English disregard for Irish welfare during the Great Famine has been argued to be genocide.

Such dynamics of power and passivity are played out in H. G. Wells' 1896 The Island of Doctor Moreau. I first came to read Moreau in response to the opening of The Adventures of Vela where Wendt makes mention of a large number of well-known stories and storytellers. Writers range from Coleridge to Mills and Boon and genres from mythology to comics and sci-fi. Historical figures and fictional characters include poet James K. Baxter, actor Wi Kuki Kaa (both of $20^{\text {th }}$ century Aotearoa), Dracula, Judas and Māui. Also present 
within the first four pages are places significant to these people or their stories (Baxter's "Wanganui Jerusalem" (4) and "Mt Vaea where RLS is entombed" (5)) and people who have become larger than life 'legends' such as Freud and Gandhi. With this heavily populated introduction to the book Wendt has made a small aperture into the world of storytelling and it's connections to world history. This four page chapter demonstrates the astronomical depths and breadths to which the novel aspires: bringing together the world's stories in a modest 276 page Samoan story. Bringing the world together in Sāmoa, the party is Sāmoa-centric. This, I would suggest, is one of the main aims of the book, given that 'Sāmoa' means 'sacred centre' and that Sāmoans do not trace their origins from another ancestral homeland, such as the Māori peoples' Hawaiiki. Rather Samoan tradition has it that Sāmoa is the sacred centre from which all peoples came, making Sāmoa's relationship with the world comparable to what Victorian era London was to the British Empire.

In The Island of Doctor Moreau, Moreau, an infamous vivisectionist in self-imposed exile, is attempting to start his own new world order with himself at the centre. The story is narrated by Pendrick who fatefully arrives on a South Pacific island where the notorious Moreau has had partial success in replicating the evolution of various animals into human beings. Moreau controls the Beast Folk as "Master" of the "Law" and his laboratory is known as the "House of Pain" $(108,149,224)$. I had began to look into this phrase, "House of Pain" in response to Wendt's words "Fale of Terror" (3) - a connection to which we will return a little later in this chapter. Discovery of the phrase's use in The Island of Doctor Moreau felt more relevant than other references I found given the South Pacific setting, and Wendt's mention of science fiction in the first pages of The Adventures of Vela. Moreover, the similarities of imagery - a shipwreck, a new race of humans, and a conflation of animal and human bodies - that finally demanded comparative treatment.

\section{"The Islanders"- making new men for a new world}

Though his beast-men have developed humanoid bodies and are able to walk upright, Moreau has had to enforce a strict social code in order to stop their natural inclinations to revert to beastly behaviour such as killing, eating flesh, and walking on four legs. Moreau himself takes the role of all-powerful Master backed, of course, by the gun. Pendrick uses the term "the Islanders" to speak of the Beast Folk (246) conflating animal-people with indigenous people.

The controversy around vivisection in Victorian England inspired great debate around the boundaries between human and animal. Evolutionary theory of the Victorian era 
conveniently fitted the scientific rhetoric surrounding belief in the superiority of the European race. One particular reason for this is that evolutionary time frames are almost beyond human comprehension. It is this difficulty with being able to imagine such vast amounts of time that led to the belief that Europeans were the most highly evolved and that other less evolved races would eventually die out. There was little understanding that survival of the fittest meant survival of the fittest for a particular environmental 'niche'. Widely misunderstood, the idea of survival of the fittest lent itself to the belief that only the overall fittest would survive and the rest would become extinct. The human species had already occupied their niches in the Pacific well before the arrival of Europeans. However, Europeans saw the darker-skinned races as inferior to themselves if not as a separate species all together thus allowing the theory of the dying race to predominate. This theory determined that inferior races would die out over time when faced with European culture. With undeveloped mental functions due to less evolved brains, the 'native' was believed to be unable to adapt technologically, to the new world that Europeans were creating in the 'new' lands. The physical inferiority of the indigene was also (mistakenly) evident to Europeans in that the natives would become sick and die in great numbers. Of course this was due to the introduction by Europeans of new diseases of which the indigenous populations had no immunity. That Europeans were justifiably terrified of dying of malaria and other such tropical diseases in places indigenous peoples had lived for generations seems to have not been regarded as a valid part of this equation.

\section{Allegorical State Housing}

Victorian scientists, perhaps did not realise that their marching on towards objective truth smacked of earlier such onward marching, and that they might be carrying with them the bones of martyrs. The desire to colonise and bring rationalism to the superstitious natives of the world has a traceable lineage of course. It had been preceded by other such romantic crusades such as the Crusades of the $11^{\text {th }}, 12^{\text {th }}$ and $13^{\text {th }}$ centuries and is still recognisable in more recent incursions into the Middle East.

As I mentioned earlier, the words "Fale of Terror" had inspired me to look into the tradition of the allegorical House. At first the words reminded me of Spenser's "house of Pride" in The Legend of the Knight of the Red Crosse (I:iv) which seemed might hold some relevance due to it and Adventures of Vela sharing the genre of epic poem. Other than genre and a general romance themology, Red Crosse and Vela hold in common a concern with questions of morality, as of course does The Island of Doctor Moreau. 
However, while the house of Pride and the House of Pain positively beg for allegorical readings, the Fale of Terror, does not. It does not insist on a such a reading because it does not need to. Such formulaic 'houses' are so commonly used to symbolise the abodes of personified moral characteristics, emotions and other personal or social traits, that the possibility of an allegorical reading of them is immediately apparent. So immediate perhaps as to bypass conscious thought as somewhat cliché. Behind this cliché however, is the possibility of complex religio-psychological allegorical reading, which links Vela's Fale of Terror to Duessa's House of Pride, Moreau's House of Pain, other literary examples, and perhaps beyond (such as fairground House of Horrors attractions) ${ }^{2}$. What this allegorical reading looks like maybe apparent in Wendt's moment of "free-flowing symbolism" (4) which features the largest concentration of mythical, fictional and historical figures. The reading prompted by this symbolist genealogy is not a simple formula where Duessa = pride $=$ Evil, plus, Moreau $=$ science-gone-mad $=$ God-complex $=$ total-annihilation, therefore, Terror $=$ Imperialism $=$ Coloniser $=$ European. While such categorical condemnation would follow in the European tradition of which Spenser and Wells are part, the idea is incompatible with the old Samoan way of seeing the world (a tradition which Wendt is part of). This move away from European world-view is mirrored in Alapati's text which flows from contemplation of the scar from a duodenal ulcer operation which has brought him and Vela together as hospital-bed neighbours.

... upright belly scar morse-coded both sides with stitch dots a wicked centipede permanently crawling upwards: Camus' Sisyphus repeating the Mountain Odysseus tied to Rock and Eagle Yeats' glad-eyed seers climbing Lapis Lazuli Mountain Maui in Hine's unforgiving tunnel Kuki Kaa fixed into my vocabulary and Baxter detailed in our coffee bar conversations and carried to a Wanganui Jerusalem which filled his questing mouth with the communion bread of aroha (Vela later admired

2 "House of Pain" appears in Milton's Paradise Lost as the name of Hell, the gates before the house of pain are guarded by Sin, the daughter and lover of Satan, and Death the resultant offspring (II: 650-760), there are connections to be drawn between the the incestual relationship that brings Death into being and the story of Hinetitama who becomes Hinenuitepo; "The House of Terror" appears in many other texts also, such as the Mexican horror film La Casa del Terror (1960) starring Lon Chaney Jr. (see Wannen). The subject matter of the film and indeed it's history connects to themes in Vela such as the curse of immortality, resurrection and the film genre itself which Wendt utilises in the climactic chapter "Final Revelations". 
my translations of Baxter's sonnets) (4)

From European philosophy and story Alapati turns our eyes to the east with reference to "Lapis Lazuli Mountain", and further still to Oceania-specifically, Aotearoa. Along with this geographical line of sight, each reference or combination of references reveals layers of the human story in regards to struggle and purpose. Such a whirlwind tour of human history deserves a longer treatment than is possible here but the the message is clear-the following text is a multi-dimensional story attempting to move the gaze of its reader from a Eurocentric vision of the world towards Oceania in order to demonstrate that in actuality there are multiple realities that make up the world. This being the case 'good' and 'evil' are similarly uncategorical.

\section{Vela is: Gandhi Christ Superstar}

Alapati does not pause long with Baxter admiring his translations in modern Aotearoa. With the move back to Alapati's present day, we are again in Moto'otua Hospital, Apia, Sāmoa in the late $20^{\text {th }}$ century and Vela's body becomes the landscape in the readers line of sight.

Enough free-flowing symbolism back to a perforated Vela sieving sleep as Mahatma Ghandi's physical reincarnation ebony hide tightly gathering in frugal bone and muscle scars not folds fat honed away by perilous journeys endured for generations a mythical creature polished to lava hardness but now caught in the solid grasp of that hospital siever of the sick and dying (4)

"A mythical creature polished to lava hardness" could very well evoke an image of an anthropomorphic volcano which, while befitting the preceding landscapes of Sisyphus', and Yeats' glad-eyed seers, definitively grounds the reader's view of the world within the Samoan landscape. The landscape seen from the hospital verandah - the "gay view of Mt Vaea where RLS is tombed for tourists" (5) - firmly brings Europe to rest within Sāmoa.

While creating these physical landscapes, Wendt also brings into being a social landscape shaped by generations of men and women living, toiling and striving. Vela, as the volcanic, carved idol, comes to represent the Oceanian men and women, and as a Samoan 
avatar of Gandhi and Jesus his body is a sacrifice, his "fat honed away by perilous journeys endured for / generations" (4). The double meaning here, of 'endured for a very long time' and 'endured on behalf of generations of people' is drawn to our attention by the use of a new line and Vela comes to represent resistance to injustice (and possibly, salvation) of humanity.

With these particular historical references, we are turned back to Alapati's and Vela's mutual existence and life purpose in relation to the Fale of Terror. Gandhi's resistance to British rule of India changed the face of human history and Wendt begins to place his two protagonists within this same tradition.

Wendt's characters however are not up against the British Empire, rather capitalistrationalist imperialism in general. Inside the Fale of Terror,

Merchants with bible-black eyes and smiles

as bright as new coins hook themselves

To the ice-blue walls inside

Assess in orderly litanies the various cuts

decide on weights and prices

The profit and sources of supply (3)

Vela's resistance, like Wendt's as expressed in "Towards a New Oceania", is against sterile materialism, homogenisation of culture via the global free market, for behind such a benevolent facade is a malevolent all-consuming force (75). "Truth is we can't live without (3).

Like the Dracula of Bram Stoker's creation, economic colonisation threatens to take over the world turning its victims into its own slaves. Wherein past English literature has compounded negative human qualities, into horrors manifested by the devil, Wendt uses horror to put human beliefs about the world into the psychological spotlight - "Dracula can be seen as the beast within, so precariously contained. He must be tracked down and eliminated" (Stott 1554). So too must the ruling "aitu of various fang shapes / and skin colour" be tracked down. Wendt wrote of them in "Towards a New Oceania", as "vampires of all colours, creeds, fangs ... [that] continue to blind us to the beauty we are so capable of becoming as individuals, cultures, nations" (74). He asserts that humanity must

try to exorcise these aitu both old and modern. If we can't do so, then at least we 
can try and recognise them for what they are, admit to their fearful existence and, by doing so learn to control and live honestly with them. (73)

First of the vampire-aitu under the pyschological limelight in "Towards a New Oceania", is "Racism" (73) which Wendt names as one of the worst aitu. Wendt writes of "Racism" as if it is an allegorical character like Spenser's Duessa, and her servants Sansfoy, Sansjoy, and Sanloy (faithlessness, joylessness and lawlessness, respectively), and like William Langland's Gyle (guile) (II.70) and Fals Fikel-Tonge (falsehood) (II.41). In Langland's Middle-English epic poem Piers Plowman, Piers is the hero of humankind, a ploughman who personifies humanity living Christ's gift of redemption on Earth, amongst his unworthy compatriots. He is, incidentally, the figure to whom James K. Baxter addressed an epistolary poem of equally scathing social critique, 'Letter to Piers Plowman' in 1952.

Through associations such as these, Wendt links Racism to those human qualities that writers of the past have lamented as hurdles to humanity living humanely. These personifications of evil such as Racism take the shape of exploitative vampires and aitu.

\section{The House that vampire-aitu built}

Wendt's conflated European vampire-Samoan aitu might seem at home in a bicultural abode such as the "Fale of Terror". But marrying the two in the first place is the difficult part for they are so vastly different beings. Aitu may be translated as spirit but there is not the same kind of negative assumption of aitu as there is of vampires: the word can also be used in place of atua, and may also be used to mean a feast in honour of a god. The name Dracula is rarely associated with benevolent powers, where as aitu are. Wendt seems to be comfortable with such a conflation, so much so that his beloved protagonist Vela is associated with the vampire. In the opening chapter of The Adventure's of Vela we are introduced to Vela's vampiric family ties; his atua is the bat and that he considers Dracula a "revered" cousin (5). However, Dracula is not the only name in the list of cousins; there are also the heroic, Batman and Batwoman. Here again is the amalgamation of malevolent forces with the benevolent. This is easily explained if we consider the position of the protagonist as being one of ignorance; at face value Vela seems merely interested in hearing stories of his "revered cousins" simply for entertainment purposes. However, the repetition of the bat motif through the novel, encourages the reader to look closer at Wendt's intentions if she had not already done so at first seeing these names together. This is especially so in regards to the role of the pe'a in Vela's ascension into the moonlit night-his attainment of liberty from life. Perhaps 
moksha is the appropriate term for this avatar of Gandhi, a fusion of great spiritual and political master, and cursed immortal and vampire. That the vampire is evil is an accepted premise in Western literature, that Gandhi is a good guy is also unchallenged; how then can the two co-exist in Vela? Patricia Grace's character Nan Kura can help shed some light on this subject.

\section{A woman of evil goodness}

Then Niecy stood and held out her one good arm to me. So I gave Baby to her to hold while we waited. She wiggled her fingers for the jar with the eyes and I gave it to her. 'I'm going now,' she said. 'I'm taking Baby out of here, taking her home,' and she went. I had been entrusted, yet here was my granddaughter, eighteen years old, deciding, taking and going.... 'Bernice, Granddaughter,' I called, but she kept on and on, not hurrying, not turning, not answering me, corridor after corridor. She stopped outside the frontdoors, holding on to Baby as though she thought I might take her and go back to wait for the policeman. 'You can't steal from us anymore Gran Kura,' Niecy said to me. 'Otherwise why did Shane die?' She was calling me a thief (65).

Gran Kura's job had been to retrieve Te Paania's stillborn baby from the hospital staff and to take her home while Te Paania's more immediate family stayed with her in intensive care. After hours of waiting patiently for them to find Baby, who had been discarded into a wastecare bin, and then being told that Baby was found but had to undergo an autopsy, and then having Baby brought to them with her eyes removed, and after waiting for the eyes to be retrieved and brought to them, they are told that they need to wait for the police to come and give permission for them to take Baby. "We'll wait"' Kura said, but inside she knew that "these were just words coming out ... coming from goodness." The "goodness" of which she speaks is one of the major themes of the book: how, for a particular generation of Māori, being good has meant being subservient to Pākehā authority and culture. She realises that her passive acceptance of authority has made her into a "woman of evil patience and goodness" (65). It has made her bury parts of herself, essential parts: her past, her language, her stories. “There's a ball inside me, a core. Round it are layers and layers, like bandages, that I've wrapped it in over the years so that it would remain hidden" (66). Niecy's actions and words help Nan realise that though those layers may have helped her to survive in the Pākehā 
dominated world there were some deadly consequences which she was no longer willing to accept.

Now, because of the children's children, and because my mouth has been opened, I must unwrap the little ball, find it, let the secrets free.

Shane wanted his name, and though this comes too late for him, I have names to give. He wanted his stories and I have these to give. I speak to you now in the language that I haven't used since the time of Riripeti. I will never speak English again. By the time I die I hope to be again who I was born to be (66).

Throughout the book, Gran Kura reveals stories from her past, many of which centre around feelings of personal or familial shame. The first one is the revelation that Shane goads Kura into immediately prior to the the car accident which kills him and Baby, leaves Te Paania in intensive care, and injures Niecy. This is the story of Riripeti that Kura connects to her "evil patience" and her abandonment of te reo Māori. It is a story that had not been told to the younger generations, one that had not been told at all. It was "a story that [had] been lived by a whole generation but that [had] never been worded" (28), because those who had lived it we're ashamed and felt the need to protect their children from it. It is this kind of untold story to which the title of this chapter refers. These stories, as well as 'positive' foundational ones, are essential centres of an individual's tātai, they are a 'core' around which one may build layers of understanding the world and one's place in it. If these stories go untold these cores, these foundations, are still there, it is just that they are unknown. Layers still build up around bones, it is just that the individual does not know that the bone is there or what it is made out of or how it may be affecting the way she lives her life. And perhaps it feels to that individual as if she is unwhole, incomplete and unstable. Shane knows that his elders hold secrets about who he is - "his name ... his stories"-and his anger will not let him rest, or "settle" (25), until these are revealed.

Seeing this, Gran Kura tells the story of how Riripeti, her teina, was "killed by school" (38) when they were children. Kura was responsible for looking after her and teaching her how to behave and what to say in that Pākehā schooling system in which te reo Māori was not allowed to be spoken. "School turned out no good for Riripeti. We were much naughtier children than what she was, that's how we knew what to do ... knew which lies were the right ones to tell" (33). Riripeti's naivety about what was necessary to survive in the Pākehā world and her honest, shy nature led to her becoming sick when faced with going to school. She 
would wet herself when smacked and vomit when made to stand in the "bad corner" which, because she was sent there so regularly, "became her corner" (34). As a child herself, Kura did not have the tools to deal with the situation or to alert the adults in their lives, and so Riripeti was killed by school. Of course, Kura, as a child, took the responsibility upon herself as she had been given the job of taking care of Riripeti. And at the same time, she blames the Māori language, for this was the major issue that Riripeti struggled with, the issue for which she was punished most often. From that moment on Kura vows not to speak Māori ever again. The child's understanding of the language as being "evil" relates to European ideas that as civilised Christians the colonisers were superior and therefore 'responsible' for the education and spiritual welfare of the darker, heathen races. The clear demarcation between good and evil, God and Devil, meant to many colonial Europeans that other religions and languages and traditions were evil. This belief is one that was taught to indigenous people all over the world. With evolutionary theory of the $19^{\text {th }}$ century came a need to reconfigure the European understanding of the superiority of white people, which until this time had been understood as originating from the word of God, that the unfortunate heathens had not yet had the opportunity to hear. The shift from Christian superiority to Rationalist superiority, then, brought into question the ability of non-whites to develop beyond their current uncivilised status. Could they actually be taught to be human, or were they intrinsically animalistic because they were less evolved species, and there for unable to become equal, unable to be enlightened, unable to be saved?

Such arguments benefited colonialists and slave-traders, but raised other questions from the dark European subconscious. European superiority acquired a strange bedfellow in the form of the theory of devolution. As Susan Hamilton notes, the turn of the century was a time of questioning the order of things and accepted boundaries. Questions of social morality such as the rights of man (eventually of women too), the ethics of slavery, democratic rule, social justice and education for all citizens, had been fomenting for a hundred years following the Age of Enlightenment. The continued decadence of the upper classes contributed to this foment, and in combination with the end of the familiar $19^{\text {th }}$ century and anticipation of the new, unknown, perhaps even 'Other', $20^{\text {th }}$ century provided sufficient impetus for the development of the devolution theory. In The Island of Doctor Moreau, Wells' passion for reformation of human society and his discomforting fear of human limitations in this regards is colourfully illustrated when Pendrick final escapes the island and returns to the centre of the 'civilised' world. It also demonstrates the fears inherent in theories of devolution. Following the death of Moreau and his henchman Montgomery, without the rule of the 
Master and his House of Pain, the beast-men continue to revert to bestial behaviour, but Pendrick manages a tense and fearful peace between himself and the animal people and manages to stay alive. On his eventual return to the safety of England he is plagued with fears that his fellow men and women will revert into beasts.

I feel as though the animal was surging up through them; that the degradation of the Islanders will be played over again on a larger scale. I know this is an illusion, that these seeming men and women about me are indeed men and women, men and women forever, perfectly reasonable creatures full of human desires and tender solicitude, emancipated from instinct and the slaves of no fantastic Lawbeings altogether different from the Beast Folk. (173)

When the terror becomes too much for Pendrick as he walks on the streets he takes refuge in a nearby church. The clergymen preaching within get special mention here: "such was my disturbance, it seemed that the preacher gibbered Big Thinks even as the Ape Man had done" (174).

Wells' somewhat oblique criticism of religious faith combine with his naturalistic contradictory statements concerning the civility of his fellow men and women where he pairs rationality with desire - "perfectly reasonable creatures full of human desires" - and tenderness sits with being free of action born of feelings, that is, "emancipation from instinct". His acknowledgement of the similarities between the animal people and the people of London in the text brings into question the foundations of European superiority whether the origin be word of God Almighty or that equally potent species of divinity, Evolution. The text makes clear the Victorian gentleman's urgent need of vigilance lest the inner beast rise to take control of the civilised man. The Cockney race, and even the Irish race, were Christians after all, and the decadence of the upper classes seemed not too far a leap from the drunken antics of working classes. And what should stop things there? Such civilised exteriors, as of the people who cross Pendrick's path, are just a facade that masks the degradation and decadence of the beast within.

Under such civilised individual exteriors there often lies some darkness that we would be loath to show in public. As sentient human beings it is hard to deny the damage that has been done in this world by people who claim to be 'civilised', genocide being the most obvious list-topper. On the individual level we may be aware that our personal actions and choices effect the other individuals in our lives. We may also understand that there is a 
broader social impact which so often takes the form of faceless statistics.

It was hard to get out of bed this morning. My kids provided the inspiration I needed to make the final push. Good kids they are. One of them was screaming at full volume GET-OUTTAHERE at the other. It had been escalating over what felt-in my stupor-like an hour, but I couldn't ignore these eardrum-bursting shrieks. I had drunk too much the night before. Not for any reason. Just lack of impulse control I guess. I like to drink, to get drunk. And I hate it. Fucks me up for a few days (during which it is sometimes easier not to drink and sometimes easier to drink more), less productive, grumpy, bad parenting, fight with my wife.

I do try to stop doing it, that and smoking cigarettes which is killing me, I can feel it now, not like when I was in my twenties. Sometimes I do really well and other times I feel like it's just impossible. I stopped for a week a fortnight ago and I was good/ontopoftheworldgood/lifeisgood/Iamgood-then lack of impulse control and all hell broke loose-shouting at my wife, swearing and slamming doors to loosen doorframes. Pretty tame, I thought, no hole $s \quad i n$ walls $t$ his time, but then it doesn't take much to get her freakedout/scared/daggereyed angry.

"Violent", she called it later, "don't deserve it, made me feel like a child, its a form of abuse" - and the rage was rising as I listened. How dare she! But I just listened (I wasn't going to be in the wrong this time). Left the house this time after a few well chosen words that clearly positioned me in the right. Let her deal with the kids in the morning!

Anger issues, who doesn't have them? At least I didn't intentionally beat some guy up on the street accidentally killing him because he had some bone disease. Brittle bones, fragile, doesn't take much to-

Those young blokes picked the wrong guy to mess with alright. Dickheads. They've got Māori names too. Pretty white looking though. (Says the albino hori himself) Are they victims too? Anger issues.

( Iain Strathern, "Read it in the paper")

The "Māori Research Agenda on Family Violence" (2008), is a governmental report put together by Te Puni Kōkiri, a branch of the Department of Māori Affairs. Māori family violence is described as "serious, entrenched and intergenerational" and "as being of 
epidemic proportions". The report states that "Māori are over-represented as both victims and perpetrators of violence within whānau" (3). Is there hope of being able to rehabilitate individuals that commit heinous crimes against the vulnerable? Is it possible to arrest the cycle of abuse, pain, anger and violence? How can tātai tara contribute to positive change in this area? 


\section{FLESH AND BLOOD}

\section{Dear Odessa,}

our poetry workshop führer said to write a letter to someone we know who could potentially write back to us I guess it depends how you define 'potentially' - I'll use poetic license.

In all these years I've never written you a letter! many poems but never a letter

When I thought about to whom to write my first thought was 'Dear Mum' but I meant the other one we wrote (occasional) letters to one another keeping in touch was never a strong suit for either of us kind of a family trait I guess

but then I thought of you

and I think it's fitting that I write this to you seeing as I received a letter of sorts while I was sleeping and I can only imagine that it came from one of youlot over there (who else sends letters via ultra secure nightfeed direct to the vault?) Don't think it was just you or even really just one of youlot. Do you ever work alone or is it all, you know, communal?

So in answer to that letter (you can share all this with everyoneelse):

Son of Batman, or The Psychology of the Batman

I think that Batman is quite insecure he really wants to be on top and he seems to pull that off for the most part good-looking rich very cool (except in the TV series) moral and physical strength a real sense of purpose and direction and loved by the masses (except when they turn on him because of some foul and felonious plot) respectable intelligent and influential not to mention humble he really is the whole package None of his fiendish foe come close (except maybe the joker as played by Cesar Romero As the arch-nemisis he even has one up on Batman a sense of humour which is a pretty big thing in life I'm sure you'll agree, Mum Youlot seem to have a pretty wicked sense of humour! I think I even laughed out loud when you guys sent me that 'wellpreserved' dinosaur-mammal-thing scared the B'jesus out of me when it looked me in the eye! I laughed out loud that I'd jumped in bed and woke up Good one youlot I thought Those old people got a great sense of humor practical jokes from the other side ha! good one!

I digress Even though Batman seems to have it all I see from your letter that it's a facade his despair as he climbed towards the top floor of that hotel was palpable and that he never reached the top and that he knew that there would be nowhere to jump from anyway and that he met his son (talk 
about skeletons!) in that shop and that he went on with life as usual shopping with him and then when his son didn't do what he was told

BAM!POW! Wo... I mean the feelings that Batman had towards his son his deep-seated insecurity of no longer being number one Did he really say he could break him like a twig?? In the middle of that shop He seemed so threatened by his son's cool smirk as he bent the young man backwards (I really like how youlot gave the son Mark's face Stroke of genius! there's nothing like a smirking tuakana to express feeling threatened, powerless, and inferior)

I guess it all may come from his traumatic childhood some residual resentment towards his parents for leaving him all alone in such a menacing world and resentment towards his son for not coming aboard the whole St Batman-the-Matyr warship A kind of he-doesn't-know-what-the-world-has-put-me-through-and-now-he's-against-metoo-

mentality Then when I thought about it after I woke up it came to me and I don't know if youlot actually knew this already but didn't want to spell it out to me (I like how you guys make me work for it btw) I thought Batman actually created the joker so what if he actually created all those villains he fights in an even more abstract kind of way what if it is all in the way that he sees the world? Maybe the world is not as menacing as he sees it maybe that resentment is directed both out at the world and toward himself at the same time for never being able to cope with the pain and torment without turning into some kind of dark animalistic freak of a god Talk about ego Man!

I really like how youlot made it about batman too I never would have got it otherwise those bats inside very cool And then how you got Elise to say the words out of the blue - "I was like Batman" — just as I was writing — "Those old people got a sense of humour" -Talk about timing!

Love you Mum.

Arohanui,

Iain

PS makes you wonder about the guy who wrote Batman nē?!

(Iain Strathern, “Epistle”)

In Baby No-eyes, the issue of family violence is brought up through the relationship of Te Paania and Shane in the form of a tenacious image of glass that pervades the novel. The boxes of glasses given to them as wedding gifts (22), glass-faced insects in Te Paania's dreams, glass doors $(14,124)$, the window that is repeatedly smashed and fixed with coloured 
glass (24), a TV-screen window, (24) and the window that is shattered injuring Tawera (2208 ), are the most obvious instances of the motif's appearance. The image of glass comes to represent an inherited way of seeing the world and an intergenerational issue of violence.

This chapter aims to explore how family violence in Baby No-eyes and The Mango's Kiss is seen as a symptom of colonial violence and repression, and how it can be a source of healing when confronted. The flesh and blood of the title, like the names of the two preceding chapters carries a metaphorical meaning as well as alluding to the actual events in the stories. To make something flesh and blood, is to make it real. 'In the flesh' signifies that a person was actually present when an event took place. As I noted in the introduction, all of the stories (and the stories within the stories) here are retellings of retellings of retellings. What 'in the flesh' means here then, is not direct experience of the events, but the experience of making them mean something - an experience which is of course absolutely direct.

My own experience of writing this thesis, making 'real' the ideas and insights that I have had in relation to the works of fiction under discussion and the process of selfexploration is one that has brought to life some of my family connections - connections with the both the living and the dead. At the beginning of my master's year I had just gotten in contact with relatives on my mum's side, a part of my genealogy that I thought I would never know. The experience answered some of the questions I thought would plague me all my life, questions I thought I would pass on to my children. Of course, it did not all come in an illuminating flash; while the contacts I made answered some questions they also opened up a whole new world of questions that I had never known to ask. Amongst them: how does the violence experienced by my ancestors (as both victims and perpetrators) manifest itself in my life? My mum's smoking and refusal to go into hospital? A kind of self-violence. Her mother's inability to care for her, to keep her safe? Parental violence. Mum's attempts at suicide? The complicity of my ancestors in the invasion of Aotearoa?

Furthermore, how do I mitigate the effects of all this history for my children? At least part of the answer to this particular question is to 'story it'. Te Paania, Gran Kura, Tawera do this in Baby No-eyes.

'If we're going to tell about the accident we'll have to tell everything.'

'We?'

Gran Kura and me, and all of us in our different ways. You too, you'll have to do your part. It could take years.' (19) 
And of course it does take years, because part of the telling is in the living of the stories making them flesh and blood.

The intergenerational issue of violence, as it manifests in the lives of Te Paania, Shane, Baby, and Tawera, is really addressed through Gran Kura's family stories. The stories trace the violence back to the death of Riripeti and beyond to early colonial times when the social equilibrium was upset by the introduction of guns. The stories tell of an act of peace made by Kura's great-great-grandfather, and the subsequent vow of peace made by Kura's grandfather, Tumanako.

He didn't go to war as some of his relatives did. When he learned that his great grandfather had put his taiaha down on the ground, he understood this to be a sign that they should give up war forever. He believed it. It was his goodness. There was [his] half-shut eye. (114)

The half-shut eye refers to Tumanako's "squint-eyed portrait" (114) but also the recurrent motif of eyes as representing ways of seeing the world. Eyes, 'the windows to the soul' combine with breaking glass to represent a 're-visioning' of the world. But the motifs move in concert with one other in particular, the hei pounamu inherited by Kura down the same line of descent.

[T]he hei pounamu made of speckled greenstone. It's like deep, milk-green river water, where the surface is so still that it has a shiny, oiled look. But when you look below the surface of the water, whether they are there or not, you see lips, eyes, fins and tails of fish, tumbling and turning. (94)

The perspective at the core of this story is a specifically Māori world view that recognises the tâtai that connects our way of seeing the world with the way our ancestors saw the world and how our children will see the world. Glass becomes the colonial way of Māori seeing the world and their place in it.

But it was as I was growing up that I came to understand the meaning of the halfshut eye. Yes, he was warning us that following generations would have to keep one eye unseeing, keep lips sealed in order to survive. That was his message, which came from goodness, love for us - but also from uncertainty because the 
world had changed forever. Grandfather did not know that goodness could rob the children's children. (108)

The view of the world that Kura inherited from her Grandfather, was one in which the Māori world was obeisant to the Pākehā world, even to the point of death as was the case with Riripeti. The motif of glass features in Riripeti's story most eloquently and subtle connection to the "milky-green" (94) pounamu is made:

we ... knew which lies were the right ones to tell. If the teacher gave us lesson about the right food to have for breakfast, when questioned we would tell her that's what we had - bacon, egg, toast, class of milk. It was the right answer bacon, egg, toast, class of milk. 'Glass, glass, a glass of milk,' the teacher would say. After a while we could say it, making this choking $g$ sound right down in our throats. But we didn't know it meant milk in a glass, didn't know what it meant. Didn't know a glass was right for milk and a cup was right for tea, because at home we had enamel plates and enamel mugs for everything. (33)

To be 'good' meant to suspend the truth, and give the "right answer" instead.

\section{Playing Up}

When Mum died, dad still had to work and did not know what else to do with me so one of our family friends helped him to get me into school early. That was the first time I remember feeling the anxiety that would so often return throughout my schooling and working life. My usual reaction to this anxiety, to suppress it and pretend that I was okay, had always increased to a point where something broke. My only 'relief' as a child was to pretend that I was sick so that I would not be sent to school; there was no way, and no one with whom, to talk about it. My father saw through the sore tummy/headache/sore throat situation very quickly and believing that I was just playing up, soon put a stop to it. So the school day passed in a state of high anxiety until I could take it no longer and told the teacher I was sick. I went to the sick bay at school and spent the rest of the day lying there listening to the other children playing or the silence of lesson times. Of course this also gave me something to be anxious about in that I was in constant fear of being discovered, caught out in my lie. It was this anxiety that led me to the decision to commit suicide sometime between the ages of 5 and 8 years old. I had been given a small brown-covered dairy at Christmas and it was in this 
book that I carefully calculated when the day would come: the day before the first day of school. I wrote a pre-countdown under the the dates in the diary - two weeks to go - ten days to go - four - three - two - one day to go - I die today. I had planned to take the sharp vegetable knife into my bedroom the night before and sleep with it under my pillow. It astounds me that I could have been so young and planning this (I still retrace the years to make sure that it actually happened when I think it did) and it astounds me further that as an adult I should repeatedly find myself in this situation and that it took me so long to connect these moments in time to that even earlier death of 'myself' in the form of Odessa. I was so afraid of going to school, but in retrospect I can see that it was not really school that I feared but the isolation that being surrounded by strangers exacerbated. In my teenage years I thankfully came to love school, mostly because I found the acceptance and laughter of a group of friends. My confidence increased year by year being with those friends and being perceived as normal, acceptable, allowing me to be unique, funny, and perhaps even cool. People to be safe with; that is what I found during secondary school, and I felt so safe in fact that I decided to leave and return to New Zealand, return to the landscapes of my birth, the land of heavy orange curtains hung on steel rings, and the scent of woodfires warming winter homes on hills. I moved in with Nana and Grandad in that happy grove in that corner of the valley called Naenae. Though there was plenty of safety with The Old-girl and The Old-boy in that other house my dad had built twenty-something years before, it was not the kind of safety in which a young man could be himself as a teenager, it was a safety in which to be a child again, and at the same time to be an old man. I had isolated myself from people my own age, and to further that I chose to work in a nursing home as a cook and cleaner. It was something that I knew, a place I was familiar with for my stepmother had worked there and my brother had cooked for another home, so I felt it was acceptable employment. It was desperately depressing for me though, and I had absolutely no way of meeting people my own age. Without satisfying relationships with my peers and my work dissatisfying to say the least, I was unhappy. It was a pattern that I would recreate repeatedly in a variety of jobs that I felt were destroying my soul. Even when I found a job with men of my own age and built some friendships the work itself was enough to move me on in search of some kind of purpose and meaning.

\section{Last Orders}

This consistent struggle in regards to purpose and meaningful occupation continued throughout the following fifteen-or-so years and in recent years took me into the funeral 
industry as a Funeral Director. Thirty years old, nearing the end of my BA degree, with two kids and a wife to support and still no career prospects in sight, my mind was turning over all the possibilities. The funeral industry entered my mind as a possible option after reading Graham Swift's 1996 Booker winning Last Orders, a story of friendship, death and farewells in which one of the characters is an Undertaker. My reasoning was that this might be a job that could fulfill my need to be of service to the community while dealing with a phenomenon that is close to my heart, that is, one which is central to who I am as a person. I sent a letter of introduction to each of the funeral homes in the Hutt Valley, including the one who had been the Funeral Director for Odessa's funeral. At the time I began the interview process my aunt died unexpectedly and I attended the first funeral I had been to since I had been a teen in Australia. Shortly after this I was employed by Harbour City Funeral Home, a reasonably recent entry into the Hutt Valley, but well established and highly respected in Wellington. I was employed as a 'Lifter' and soon progressed to Trainee Funeral Director. A number months later my uncle in Australia had a sudden heart attack that killed him at the age of 60, and only a week later 93 year old Jackie, Grandad, fell, broke his hip, and died a few days later. Also during this period Elise and I separated for about 3 months. It was a turbulent and stressful time.

With time life stabilized. Elise and I got back together and made some positive changes, my employers were happy with my work, everything was going well, but for one thing - a familiar feeling of emptiness and anxiety that was becoming a constant companion now that life was less dramatic. Looking back, that familiar feeling was so normal to me that I did what I have done since I first felt it as a child sent off to school as soon as my mum died. I pushed it down and tried to get on with it. So many times has an occupation I have had for a few months or a year or so ended in this way. Not being able to cope with stress and numbness, and finally succumbing to depression. As a Funeral Director there were so many things to organize, remember and keep track of at one time and my mind started to feel like a steel trap without a spring, and rusted joints, and dull teeth ...

Finally after my busiest week in the job, organizing three big funerals, one Catholic, one Greek Orthodox and one ex-military, something gave way and I could not go to work the next day. As I had done so many times before I pretended to be sick; this time very sick. I made myself sick with the anxiety and wanted to die and believed I would be able to by willing it to happen. 
don't want this grief

to end envelop me

crush life from the core

don't want to write

words might help

me heal-anathema!

drown in grief

go down to the sea

bed not to wake again

anguish if you would

be my exit from this cold

the world without-

never sleep again knowing

the sun will

rise on me without-

cruel death I don't want

her back - only to go too

why leave me poised

hanging here hanged and

limp and living still

merciful death in your hands

wring life from the core

let pain do its work

on this frail earthly frame

let the sun not rise on me

your worst and I'll rejoice

do not take away this pain

(Iain Strathern, “de Lyon”)

After a few days of willing myself away, a friend helped drag me out of my self-induced stupor and I called my counselor and told him what had happened. Speaking to my counselor that day I realized for the first time that I had a problem with anxiety; we had spoken about it in the past but it had never sunk in until then. I felt as if I would not be able to return to work, 
but after a session with the counselor I determined to try one more time, even though I was absolutely terrified of going back. I had a meeting with my employer and they decided that from their perspective it was too risky to keep me on after the end of my contract which was coming up for renewal in three weeks time. I managed to work out the rest of my contract and started on antidepressant/anxiety medication.

\section{"There was some consolation: they paid me well"}

Skeletons have a way of making us into things that we never would have imagined, that we never saw coming. Take for example the character Barker in Wendt's The Mango's Kiss.

For almost five years Barker lived off his wits by selling his body, in London, with his [deceased] mentor sitting in his centre of grief. Alcohol, opium, the flesh. It was as if he were watching someone who resembled him caught in a fog, trying to find his panic-stricken way through the beasts and the preying creatures that inhabited that trap.

Human beings are such sick and monstrous creatures! Powerless, penniless, they fed off me, and I suppose, I fed off them. Behind the benevolent face of Queen Victoria was madness and sickness. (Sin and abomination you call it, Mautu)....

At one banquet, held by one of England's great lords, I was literally served up on a platter. They dressed me up as a sucking pig, even with an apple in my mouth, and carried me to the massive dining table on a golden platter. The civilized lords and ladies took turns eating me. It was Sodom and Gomorrah, Mautu. And they loved it. There was some consolation: they paid me well. (215)

However, such skeletons help to make us what we are if we can learn to live with them rather than letting them control us. Like the vampire-aitu that Wendt writes of who rule the Fale of Terror and so often seem to rule the world, our own personal demons can make us slaves to their machinations. Barker, acknowledges that he too "fed off" of others. He was a victim of society and history; in today's terminology he would be 'just another statistic'. However, he did not finish his days as a mere statistic, he died a self-styled self-exiled English lord, a bornagain pagan, and a legend. How did he do it? His embrace of the dark side seems to have something to do with it. 
The dark side of humanity that Albert Wendt explores through Barker is a more complex beast than one might expect on hearing such words as 'the dark side'. One automatic association might be the Darkside of George Lucas's Star Wars films. Of course, this struggle between the forces of Light and Dark are familiar to us from much older cosmologies such as Manichaeism and Christianity. The Mango's Kiss explores the complex relationship between the light and the dark sides of humanity, in relation to Samoan religion in the early twentieth century. Traditional attitudes towards sexuality, paganism, and magic were repressed (outwardly at least) in colonial Sāmoa by Victorian conservatism, challenging long held beliefs in the beneficent, albeit potentially dangerous, aspects of Darkness as a natural phenomenon that compliments the light.

The analepsis that occurs through Peleiupu's reading of Barker's letter fits neatly into the genre identified by David Punter as decadent gothic. The genre employs themes such as sexual excesses, abuses of wealth and power, the cult of the self, human devolution, and even the threat of reverse colonization. The four great novels of the decadent gothic are R. L. Stevenson's The Strange Case of Dr. Jekyll and Mr. Hyde, Wells' The Island of Dr. Moreau, Bram Stoker's Dracula, and Oscar Wilde's The Picture of Dorian Gray. The influence of such works is noticeable in many of Wendt's works, particularly The Adventures of Vela and The Mango's Kiss, and especially in regards to Barker. Barker is the only Papālagi living in the Samoan village of Satoa just before the beginning of the Twentieth Century. In theory, colonial theory that is, Barker, as a European should be more 'civilised' than the Satoans. However, Barker problematises the colonisers' simplistic version in which European = civilised $=$ good $=$ Light, and South Sea Islander $=$ cannibal $=$ evil $=$ Darkness. In line with historical realism, Barker does not fit the equation. He is a "renegade beachcomber" (331); resident merchant-trader, an exile and an atheist, he is a character reminiscent of Stevenson's The Beach of Falesa. Barker has left so-called civilised society behind and refuses to embrace Samoan society or the new religion of Sāmoa, marginalising himself and his Samoan wife and their children. Thus, unacquainted with Sāmoan etiquette and unenlightened by Christianity, he is considered doubly uncivilised by the Satoans.

Nonetheless he and Mautu, the pastor of the village of Satoa, become fast friends. Mautu is descended from a line of great taulaaitu and taulasea, traditional priests and healers. Mautu's denial of 'magic' in the form of traditional Samoan divination and healing, has sapped him of his spark for life. The village has embraced Christianity and has discarded aspects of their former spiritual traditions that the church has deemed pagan and contradictory to the socalled 'one true religion' such as the wearing of tâtau, the reading of dreams as spiritual 
messages, and communion with natural phenomena. Through 'storying' to him tales of the world outside Sāmoa, Barker reawakens a sense of adventure and passion for the world in Mautu that leads to the two of them prospecting for gold together. This is also the first in a series of episodes in which Mautu helps to foster an almost non-existent spark of spirituality in Barker. The unfolding of Barker's spiritual life takes place alongside his deepening relationship with Mautu and his daughter Peleiupu, which provides him with an emotional basis for his embracing of Samoan traditions, some of which are traditions from the days of "Darkness" (162) as pre-colonial times are called by the Samoan characters in the book.

In this first episode, the two men strike metaphorical - or perhaps more appropriate, metaphysical—gold. Wendt uses the tradition of tales such as Treasure Island, but transforms the adventure, and the men, when they discover a more grisly treasure in the form of human skeletons. "The children [Mautu's daughter, Peleiupu, and son, Arona, who were accompanying the men] cringed. It was a human skull. In the blue light, it looked so nakedly white, veined with black mud" (60). The moments following this discovery are revealing of the cultural negotiations between the two men in a moment of tension and noncomprehension that is rare between these characters. It is this negotiation, rather than adventure that becomes the centrepiece of the episode.

With his hand Barker brushed all the dirt off it. 'Wonder how it got here?' he asked, poking his fingers into the skulls eye sockets.

'We go now!' Mautu said to him in English. The children gathered the implements quickly.

Barker saying nothing, started digging up the ground around where the skull had lain. Peleiupu could feel her father's mounting anger as he stood watching. Bit by bit, as Barker dug, a broken human skeleton was revealed.

Panting heavily from the exertion, Barker asked, 'It's so far inland-how did it get here?'

Mautu had no answer. 'Let's go home,' he instructed his children.

'But it's early!' insisted Barker. 'And there's nothing to be afraid of.'

'The message, it is clear,' Mautu said in English. There is nothing here, not now.'

'But the mystery ...

... 'We leave it alone!' Mautu said. It was an order. (60) 
Barker remains however, and, determined to uncover the mystery, uncovers more skeletons. Mautu, realising that he has a responsibility to the bone people, rejoins Barker the next day and each day for a week. Mautu compels Barker to help him exhume all of the remains and they discover that the people had been slaughtered in battle. With solemn ceremony the remains are interred in the village. All the while, Barker has maintained that they are just "harmless ... useless bones" (63) but he comes to realise his own responsibility for them also. “'I suppose being human beings like us they need to be buried decently ... And after all, we found them and are therefore equally responsible for them. You can say we are now their family! ... You can say that we even struck gold!"” (67)

Barker's conversion to the fa'aSāmoa, happens almost entirely off page. Instead of seeing Barker's journey unfolding through his eyes and thoughts the reader comes to an understanding through Peleiupu and her exploration of her connection to the spirit world. Getting to know the spirit of the land and the wisdom of dreams, Peleiupu guides the reader's discovery of this Other way of seeing life. Wendt intersperses Pele's discoveries in amongst Barker's journey so that the reader is led to intuit what actually happens to Barker spiritually, rather than actually reading it. There is enough ambiguity for the reader to be questioning what 'really' happened long after putting the book down. It is this ambiguity that gives the characters life beyond the pages. Satisfying as a whodunit might be in it's neat conclusion, it is often the discomforting raggedness of ambiguity that feels most real, and satisfies on a different level. My point here though is beyond the roundness of Wendt's characters; tātai tara are ambiguous also because they are real and 'facts' get mixed up, misconstrued and misrepresented. This does not make them less useful or potent, it actually makes them more so. It is the unknown elements in our tātai that keep our ancestors alive in our hearts and minds, as much as the known parts. Without the skeletons in the closet there would be nothing to dig for, nothing to keep our minds turning over their lives even as we sleep. As we turn over their lives, be it in sleep or on the page, we are guided by them in our own lives. Interestingly, just as in the case of Barker one does not even need to believe in a spirit world for it to work. Just as we gain insight into our own lives and relationships from turning over the stories of Peleiupu, Mautu, and Barker (and by doing so make them live beyond the page) so too do we do this with the characters of our tātai.

Barker's initial skepticism makes him a zealous convert. The negotiation of cultures that occurs in his relationship with Mautu and his family leads to him becoming sogo'amiti, one who wears the tâtau, both furthering his reputation as a pagan, and ironically earning him a certain guarded respect from the people of the village. The common name for the male tātau 
is pe'a, a word that also translates as "bat". Wendt's discussion of tātau in his 1996 essay "Tatauing the Post-Colonial Body" provides some fascinating material for discussion of Barker, which we will return to later in the chapter.

Following his tātau, Barker determines to build an alia, in Barker's words: "'a ship to outspeed anything, even death"' (138). This new project, comes with the ambiguous and secretive revelation that he has contracted the fatal Satoan disease that only effects people of that village. If true, this would mean that Barker has somehow become a Satoan; no longer a foreigner who merely resides in Satoa. Peleiupu's close relationship with Barker drives her to find a cure for this disease, and she learns that it only effects those who actually wish to die. Yet, Barker is at his happiest and manifests no signs of the disease furthering the ambiguity of the situation. One early morning Peleiupu dreams about Barker. She dreams of the alia, "white as bone, black mast veined with fissures, and winged with a white sail fat with the wind ..."

Suddenly (and she didn't want to see it) she was kneeling on the deck that joined the two hulls, beside a corpse that was covered up to its neck with ie toga. She leaned forward but a blinding light burst up and out of the mound of mats, and, as her mouth started swallowing the light, it turned into a solid, choking liquid that tasted like blood. (138)

The dream, also ambiguously neither all good nor all bad, neither all comforting nor all terrifying, quite unambiguously foretells Barker's death and his transformation.

The dream is reminiscent of two gothic descriptions of note, the first treated by Carol Senf in her essay “'Dracula': The Unseen Face in the Mirror” is a scene from Stoker's Dracula in which Arthur, one of the vampire-hunters, kills his fiancee Lucy who has been transformed by Dracula. Senf describes the killing of Lucy by her fiancee as "filled with a violent sexuality ... the scene resembles nothing so much as the combined group rape and murder of an unconscious woman; and this kind of violent attack on a helpless victim is precisely the kind of behavior which condemns Dracula in the narrators' eyes" (165). "Arthur never faltered. He looked like a figure of Thor as his arm rose and fell, driving deeper and deeper the mercy-bearing stake, whilst the blood from the pierced heart welled and spurted up around it. His face was set, and high duty seemed to shine through it"' (164).

Senf points out the similarities between the 'good' vampire hunters and the apparently evil Dracula. The narrators insist that they are agents of God and are able to ignore their 
similarity to the vampire because their commitment to social values such as monogamy, proper English behavior, and the will of the majority enable them to conceal their violence and their sexual desires from each other and even from themselves. Stoker, however, reveals that these characteristics are merely masked by social convention. Instead of being eliminated, violence and sexuality emerge in particularly perverted forms.

In a short article posted on University of Sterling's “The Gothic Imagination” website Jennifer Brown quotes the words of Cardinal Roark from 2005 film Sin City, regarding the cannibal, Kevin: "the eating, it filled him with white light ... he didn't just eat their bodies, he ate their souls ... he swore to me that he felt the hand of God". Brown links this description to the social status of the bad guys in Sin City, they are "figures of authority in the church and society, they are wealthy, they are policemen. They are supposed to be the pillars of society". Brown points out the possible political and perhaps spiritual message that lies beneath, "Are [they] suggesting that those in power are feasting on the little people? Are they telling us that we will be eaten alive if we continue to put our trust in corrupt leaders?"

This description, "It filled him with white light ... he swore ... he felt the hand of God", read alongside the scene from Dracula - "Figure of Thor", "mercy-bearing stake", "high duty seemed to shine through [his face]"- suggests that motivations of vampire-slayer and cannibal may be more similar than at first they seemed. Power. Divine power. But how does this relate to Barker? He is no vampire-slayer nor cannibal. Well, actually he is both. In the posthumous retelling of his life's story, through the letter left with Mautu to be read only after his death Barker, reveals that he was not a Lord as he had claimed in life. Rather he was an orphan, a prostitute and a murderer. "One day I broke from [drunken unconsciousness] and I was in the orphanage of my childhood" (215).

Nursed back to health and society by his old teacher Elizabeth Thrombone, Barker is eventually asked to join the staff of the orphanage by Elizabeth who runs the orphanage with Roger Smiles, her "husband who could have come out of Dickens" (215). Barker soon becomes aware of the fear with which the rest of the staff regard him except for the oblivious Elizabeth. Smile's speaks of the orphanage as "one big happy Christian family" (219) that saves “'God's beautiful children"” (219), but Barker discovers Smiles's prostitution of the some of the orphanage children and staff members for the pleasure of Lords and rich colonial merchants and the likes (216-17). One evening Smiles forces Barker to witness his own sexual abuse of two boys and through some kind of helplessness Barker does nothing to stop him. "Suffice to say, it was a story of the kind of abuse I was used to - the total humiliation of the innocent and powerless" (220). 
Smiles, is representative of the dark, decadence of Victorian English society and more broadly of the human traits of fundamentalist repression of desire and its extreme counterpart, hedonism. The Christian and Victorian suppression of sexuality, Paganism and magic led to the emergence of perverted incarnations of these. Barker uses Smiles sexual desires against him, executing an horrific plan of retribution. After seducing Smiles into sexual and emotional trust, using silk straps Barker ties Smiles to the four corners of the bed telling him that he has "many surprises for him that night" (221). Two of the surprises appear in the form of Phoebe and Clarise, two staff and ex-wards of the orphanage, dressed in black like Barker. Beginning with theatrical, bondage-play that delights Smiles, the three soon leave behind the pretenses, and Smiles becomes gripped with panic, but gagged with another silk strap he is unable to scream when the "lacerations [caused by their whips] opened and poured blood" (222). The scene resembles an exorcism presided over by a necromantic "'undertaker"' (222) and assisted by Shakespearian witches, or worse still, a vivisectionist assisted by female converts.

The women, faces contorted with triumphant rage, danced around him ... his eyes silently screaming and screaming. A knife seemed to have grown out of my right hand and was wielding me as its weapon. My left hand was around Smiles' manhood ... and the knife dug in and around, cutting swiftly, and I was looking up at my upstretched arm and hand, holding aloft Smiles' manhood, which dripped blood until my whole arm and shoulder were covered with it. When I looked again, Phoebe's knife flashed across Smiles' taut, protesting throat, and his eyes were turning inwards to his disbelief that he was going to die. His body jerked once hugely, and I pushed down on his chest to try to still him, but it jerked again, and again, as if it were shedding his evil, his life - shedding it forever, like a skin it had outgrown." (222)

The analepsis of Barker's letter takes us out of the Samoan world we have become familiar with and into a genre of writing that was popular at the time in which it is set, thus confounding the 'real', $19^{\text {th }}$ century London with the fictional one. By extrapolation it is possible to imagine a London in which Barker, Phoebe, Clarise, and Smiles exist along with Dracula and his brides, and the vampire hunters. From this London Moreau has exiled himself, the Boer war is being fought in Africa, and the land wars in Aotearoa are just passed. This reinforces a key theme, what makes one text historical, that is a true representation of events passed and another too fantastical to be true? With less historical-realism than the main narrative, Barker's revelation mirrors the heightened state of anxiety of the gothic. 
What effects might this analepsis have on the reader; what does the novel gain by such a shift? In Mark Ellis's The History of Gothic Fiction he examines the question of why readers enjoy being scared. He comments on Anna Letitia Aikin's theory from 'On the Pleasure Derived from Objects of Terror', published in Miscellaneous Pieces in Prose (1773) authored with her brother John. Ellis writes "The supernatural, Aikin argues, offers an expansive field of the imagination in which anything may happen. In part, then, terror and the supernatural is a matter of epistemology: an opening out of imagination that leads to amazement and bewilderment" (9).

Wendt's use of the gothic in The Mango's Kiss makes use of this aspect of terror to encourage the expansion of his readers minds and by juxtaposing it with Samoan traditions of the supernatural he makes the connection between the potential of European gothic to expand the mind and Samoan supernatural as a healing force.

A strange and unexpected event awakens the mind, and keeps it on the stretch; and where the agency of invisible beings is introduced, of 'forms unseen and mightier far than we', our imagination, darting forth, explores with rapture the new world which is laid open to its view, and rejoices in the expansion of its powers. Passion and fancy co-operating elevate the soul to its highest pitch; and the pain of terror is lost in amazement. (Ellis 9)

With the success of his plan, his mind and soul elevated to their highest pitch, Barker leaves England forever. "I was free, at last. Free of Smiles, of any guilt to do with his dramatic demise, free of my grief and free of that sick country, Great Britain" (Wendt, Mango's Kiss 223). This success purges Barker of a beast within himself, a beast representing the way of life that imprisoned him as victim of and accomplice to abuse and hypocrisy that flourished "behind the benevolent face of Queen Victoria" (215).

Yet it takes more than destroying Smiles and self-imposed exile from English society to complete his transformation. He must die before he dies, extinguish himself before he is consumed in the divine flame. Barker's transformation-from the dark, decadence of 'enlightened' English society-into a man lightened of his cultural burdens by the Samoan 'Darkness', and his 'absorption' into the Samoan landscape are mirrored in The Adventures of Vela, where European authors, characters and their landscapes are subsumed by Sāmoan ones. Barker represents the opportunity for Europeans to learn from Samoan culture, not as scientists studying primitive humanity but, as equals. However, the moral of the story if one 
can call it that, is aimed more towards the Oceanian, just as it was in Towards a New Oceania. Seeing the reality from an Oceanian perspective is as valid as any European world view, and moreover, is more valid for Oceanians.

Colonisation, globalisation, fiscal imperialism, racism, misogyny, and violence all have a lot in common. One thing that they have in common with each other and with genres such as romance, and horror is the utilisation of the rhetoric of the Good, "we must bring civilisation to the savages for their own good", "we must control the poor, the feminine, the Other for the good of society", "we must destroy the axis of evil / zombie invaders for the good of humanity". Wendt draws attention to the inevitable abuse of power due to motivations of those who seek power (that is, human beings) always being less than pure. Recognising that life is messy, Wendt's response is to story it. There is no way to go back, there is no golden time to go back to. There is no utopia which can be created. The closest we may come to utopia is in the narratives we believe about the world, the stories that we move forward with, a post-modern utopia where vampires can be the good guys too.

Barker heals, becomes whole, within the supporting structure of Mautu's aiga. Wendt's fusion of personal (hi)stories, socio-political and philosophical theories, and mystical spirituality, expresses the connection between the individual, his or her family and community and the spiritual world in a mirroring of gafa connections. In this new family, Barker is able to "exorcise" himself of the aitu that "continue to blind [him] to the beauty [he] is so capable of becoming" ("Towards a New Oceania" 73). Wendt's words were originally aimed at the "individuals, cultures and nations of Oceania" specifically. However, when read in conjunction with The Mango's Kiss and The Adventures of Vela it is clear that while Wendt's primary concerns are local he aims beyond the transformation of Oceanian individuals and societies, towards the global community.

How the world might be transformed by an embrace of Oceanian world views is represented in the journey of Barker, and Wendt's 1996 "Tatauing the Post-Colonial Body" provides some greater insights into such a transformation. The colonial project of 'civilising the savages' of the South Pacific was often troubled by the civiliser becoming enamoured with the 'savage's' way of life. Many, Europeans desired to 'return' to ways of living that seemed to be simpler and less corrupt. Some saw the South Pacific as a place where this could be achieved: a potential new Eden (Thaman 5). In the cultural negotiations that ensued many Europeans were converted like Barker. ${ }^{3}$

3 See Manning, Frederick Edward. Old New Zealand: being Incidents of Native Customs and Character in the Old Times. By A Pakeha Maori'. (1863) Project Gutenberg. <http://www.gutenberg.org/ebooks/33342> 
As the people of Sāmoa converted to Christianity through the process of colonisation, so too did Barker convert and as mentioned earlier, in doing so, he put on the habit of his new religion, the pe'a. As Wendt points out in "Tatauing the Post-colonial Body", "tattooing ... is to do with the blood, human blood, with deliberately bleeding the body, the flying fox is the bat is Dracula is Batman is vampirism is leeching" (96). Thus, Barker (even down to the flying fox smell) is Vela, and like Vela he returns Samoan culture to the centre. Vela does so by 'storying' Nafanua into the leadership of the Christian religion and creator of various elements of Western culture. Barker stories Europe into a Samoan world, eventually becoming one with Sāmoa, putting himself (a European body) into the sacred centre.

Wendt makes the connections subtly with the black and white of the skull and the black and white of the alia in Pele's dream. "Tatauing the Post-colonial Body" makes clear the connection:

You may ask, what colour was the Post-Colonial body I saw? I didn't see any colour, just a black human outline on white paper. (All the meanings of Franz Fanon were conjured up by this.) But by giving it a specifically Samoan tatau wasn't I turning it into a Samoan soga'imiti? Yes, in one instance, but nonSamoan males have been tataued and non-Samoan women have been malued. Fair skin has always been considered ideal for tatau because of the black on white contrast. (86)

This insight may present us with an opportunity to re-evaluate Barker's persona during the bloodletting of Smiles that ultimately led to his own bloodletting in Sāmoa. Let us compare Barker's treatment of Smiles to the account of Englishman, John Rutherford's forced tā moko in early $19^{\text {th }}$ century Aotearoa (Waldie 25):

we were ... held down by five or six men, while two others commenced the operation of tattooing us.... an instrument made of bone, having a sharp edge like a chisel and shaped in the fashion of a garden-hoe, [was] immediately applied ... to the skin, striking it twice or thrice with a small piece of wood. This caused a great deal of blood to flow.

Waldie, A. J. "Richard Barrett: Pakeha-Maori." The New Zealand Railways Magazine 13.2 2 May (1938):

38-40. <http://nzetc.victoria.ac.nz/tm/scholarly/tei-Gov13_02Rail-t1-body-d15.html>

---. "John Rutherford: The "White New Zealander"." The New Zealand Railways Magazine 13.8 1 Nov.

(1938): 25-28. <http://nzetc.victoria.ac.nz/tm/scholarly/tei-Gov13_08Rail-t1-body-d7.html> 
Recall that in the 'operation' on Smiles, "lacerations opened and poured blood" after he had been restrained with silk straps. One such strap was used to gag Smiles who was silent thereafter, only able to 'scream' through wide open eyes, while Rutherford relates that "although the pain was very acute, I never moved or uttered a sound" Furthermore, as Rutherford is attended by "the chief Aimy's daughter [who] several times wiped the blood from [his] face with some dressed flax" Smiles has Phoebe and Clarise who whip the blood from his body. In the case of Smiles, the end result is a convulsion which created the appearance that he he was "shedding his evil, his life - shedding it forever, like a skin it had outgrown" (222). Barker, then, may be viewed as the tufuga ta tatau, the master presiding over a rite of passage, providing the initiate with a new skin.

In "Tatauing the Post-Colonial Body", Wendt uses the term "bloodletting" to describe how he perceived the experience of two non-Samoans who where tataued. Bloodletting holds connotations of letting out bad-blood, and though he does not mention it here it is evoked forcefully in Barker's confession. 'Confession', 'bloodletting', 'catharsis', 'purging' - Barker certainly had his own share of Western-rationalist skeletons, but what healed him was not simply letting them out, he had to replace them with something else. What was it that he put in their place? In Wendt's explanations of the basic motifs at the disposal of the tufuga ta tatau he notes that "[t]he single line is called aso ... that is the name of the ribs of the roof of the fale. Ivi asoaso are also your ribs" (93). Aso also means "day", a seemingly unrelated piece of trivia. However, asoaso is many days and furthermore, Pratt records other meanings of aso as "A daily offering of food to a chief" and "A day's offering of a human victim" as in the phrase "Se! ina sae ane o lo oulua aso. [Meaning] Skin your day's offering” (77).

The Maori word aho translates as fishing line, but also "line", showing a likely etymological connection to the aso motif of a tatau which, is supported by another meaning"line of descent, genealogy" (Moorefield). All of this without reference to the iwi-ivi connection. But of course there is one; the Māori aho tuaiwi, translates to English as "spinal cord". Ivi asoaso the ribs, connect to the tuaiwi, the spine, containing the aho, the line, the line of descent, spinal cord, the aso, the day, the rafters, the daily offering, the sacrifice, the aho, a "medium for an atua in divination" and "radiant light".

One translation of the Māori, papa, is a "victim, sacrifice". Whakapapa, then, may be considered "to sacrifice", just as tātai is to adorn, to recite or trace, plan, to ebb and flow, and to calculate. To sacrifice our blood and bones, our flesh and skin, for the generations to come is not a purely Māori or Oceanian sentiment. It is a human one, common to all cultures. But 
why? Is it just a deep inherent desire for our genes to continue - to have some kind of immortality? Is it just the survival instinct extending to an instinct to defend those who have come from us? Is it that there is a need to make our mark in the world, leave something that will last the ages? Something as close to indelible as we can come? Is it the desire to inscribe on existence that "I was here"? Making the world mine-I have a claim, it has my name on it. And the names of those from whom I came forth and the names of those that issue from me. A tattoo of the beloved's name on the arm, shows that she belongs to me and I will always belong to her. We tatau, tā moko, tātai, talagafa our identity on to the earth with chisels made from bone. Dipped in blood, we apply them to the skin of the earth, striking to pierce (or Piers?) into the flesh. We give of our blood, and the blood of our children, that we might be fed and nurtured by hers. In this way we continue to adorn our primeval mother and we look to our whānaunga who still make the father's kahu beautiful, to guide us in our endeavours be they cultivating or navigating, tātau or tātai, talatala or tuhia he kōrero tara. 


\section{Conclusion}

The dead do

sing in us, in

us and through

us, and to themselves

under their mounds of earth

swelling in the sun, or in their

ashes that shine

as they depart on the wind.

See how the grass

sways to the sound

of their voices

under, singing

the beautiful

eternal sadness

of before

relieved of the

resolve of after.

(Brian Turner, “After”)

Sharing sob-stories

Everyday I deal with the difficulty of getting moving, fear of meeting people and speaking. I deal with the anxiety around my working life and what I am going to do with myself and I deal with the feeling of emptiness that has been a long time companion. I know these are not extraordinary things that I deal with everyday, they are normal human struggles and I know that there are many people out there who would love to have only these concerns to deal with.

I wrote that a long time ago, relatively speaking, I mean. I would like to take it out of this 
thesis, it's not true anymore, you know? I don't feel like that anymore, and I intend to never feel like that again. So I could really just take it out for good. After all, as Thomas King said about his own sob story, "So what? I've heard worse stories. So have you. Open today's paper and you'll find two or three that make mine sound like a Disney trailer" (8). Of course the fact that you are reading this, means that I have already decided to leave it in, if for no other reason than to remind myself that once upon a time I did feel that way and I was able to move through it. More than that though, it might help someone else one day to know that one can feel like that and move through it. It could be one of my daughters or perhaps a grandchild of mine someday. There is another reason to leave it there. Thomas King went on to write

Matter of fact, the only people who have any interest in either of these stories are my brother and me. I tell these stories not to play on your sympathies but to suggest how stories can control our lives, for there is part of me that has never been able to move past these stories, a part of me that will be chained to these stories for as long as I live. (9)

The only thing I would rephrase is that there are only two people with any interest in those stories; I might say 'invested interest' just for clarity. I think this is what King might have had in mind, considering that he left them in too. And I found them of interest, and I know a lot of people who love The Truth about Stories, and can appreciate hearing about the most influential events in any person's life no matter the level of tragedy. Instinctively perhaps, we understand the point. To tell one's story is to lighten the load, not by lessening the weight of it or to pass it off on another but to ask for support. Most listeners are more than willing to give at least this much, just as a cinema-goer is willing to invest herself in the life and emotions of an onscreen person. The stories of others resonate with our own, often reinforcing the mana of our own life narratives. Patricia Grace has often said and written that when growing up there were only books with European protagonists. Certainly none of the heros were Māori, and this inspired her to tell our stories on the page. So, if the stories of foreigners, Others, can inspire us and help us to uphold our mana, how important, how essential, how life affirming and healing are the stories about $u s$ ?

\section{The stories of my telling}

Sharing our sob-stories helps us to make them flesh-and-blood real. Helps us to really own them; otherwise they will stay skeletons in a closet of skin. Making them flesh and blood 
we recreate ourselves over and over like cells regenerating. Like cells regenerating, the flesh and blood of the stories and ourselves will age, mature and finally come to an end and a new beginning.

I have hope that things will change and that having better insight into my grief, emptiness and fear, I will be able to move forward more positively. There are many obstacles to overcome; a dependence on tobacco and alcohol, which saps me of energy and causes me to be angry, withdrawn and irritable. I have a strong need for creative work, regular physical activity, and spiritual connection and I struggle to integrate these into my everyday life.

Increasingly it becomes less of a struggle and more a happy duty. So much so that we have started to make plans again, wanted to make plans, actually felt able to live life. My wife and I, and our daughters, Odessa and Mara, are embarking, or re-embarking on an adventure this year. Having decided to take our kids out of the still very eurocentric school system in favour of homeschooling, we hope to ensure that our children have a strong grounding in the stories that make them who they are, the stories that are their past and therefore their future. The story that relates to their grandmother will always be a sad one, eternally sad, to paraphrase Brian Turner. Though when I tell it to our two girls, born of my tātai and Elise's equally story-filled whakapapa, the story will be sublimely beautiful just like them. It is a story of hope and survival, as much as it is a story of death and sadness. I choose to tell of the hope with which my mother approached life and how it is within me also. It is not an unlikely story for it is one that has been lived by many people before me. And the longer I live the better I come to understand that those many people before me are not just strangers, they are the flesh of my flesh, blood of my blood, bone of my bone, and even the skin of my skin. Furthermore, they are the whenua of my whenua and the kōrero tara of my kōrero.

couldn't see the field for all the blades nor the Earth for all the dirt

He never saw the shore for the sand drift wood exoskeletons footprints of people

animals

nor the horizon for the waves and the sky 
I never saw the soul for the slave and the profit he made

me

you never saw the wind for the dust

In your eyes I never saw the depth for the

piercing

to anthropomorphise is not human

she looks like a pou of all my

ancestors stacked

one on top of the other but fallen like a blind old giant only parts of her showing above

the tide

ūpoko nose chest and puku thrust up to

Sky

Who carved you Kāpiti and do you stretch to Clydebank? a sunken causeway for my ancestors to meet to speak of what we did not see for gazing

(Iain Strathern, "The Roof Still Stands") 


\section{References}

Allen, Chadwick. Blood Narrative: Indigenous Identity in American Indian and Maori Literary and Activist Texts. Durham: Duke UP. 2002. Print.

---. "Rere Ke / Moving Differently: Indigenizing Methodologies for Comparative Indigenous Literary Studies." Comparative Approaches to Indigenous Literary Studies. Spec. issue of The Journal of New Zealand Literature 24.2 (2007): 43-72. Print.

Barnhart, Robert Knox; and Sol Steinmetz. "Chambers Dictionary of Etymology". Chambers Harrap, 2003.

Baxter, James K.; Louis Johnson and Anton Vogt. Poems Unpleasant. Christchurch: Pegasus Press, 1952. Print.

Corr, Charles A., Clyde M. Nabe , and Donna M. Corr, Death and Dying, Life and Living. Belmont, California: Wadsworth, 2003. Print.

Camus, Albert. The Myth of Sysiphus. 1940. New York: Vintage, 1991. Print.

Charlot, John. "Aspects of Samoan Literature II. Genealogies, Multigenerational Complexes, and Texts on the Origin of the Universe." Anthropos 86, 1.3. 1991: 127-150. Print.

Cherrington, Lisa. "The use of Māori mythology in clinical settings: Training issues and needs." The Proceedings of the National Māori Graduates of Psychology Symposium 2002. Print.

Ellis, Markman. The History of Gothic Fiction. Edinburgh: Edinburgh UP, 2000. Print.

Fanon, Franz. Black skin, White Masks. London: Pluto, 1986. Print.

Grace, Patricia. Baby No-eyes. Auckland: Penguin, 1998. Print.

---. “The Maori in Literature.” Tihe Mauri Ora: Aspects of Maoritanga. Ed. Michael. Print

---. “The World Where You Are: The 2008 Neustadt Lecture.” World Literature Today 83.3 May/ June (2009): 28-31. Print.

Grace, Wiremu. "How Maui got his name." Careers NZ: mana rapuara Aotearoa. Careers New Zealand, 2012. Web. 1 Feb 2013.

Hamilton, Susan. "Still Lives: Gender and the Literature of the Vicorian Vivisection Controversy." Victorian Review 17. 2 Winter (1991): 21-34. Web. 21 May 2011.

Hau'ofa, Epeli. "Our Sea of Islands.” A New Oceania: Rediscovering Our Sea of Islands. edited by Eric Waddell, Vijay Naidu, and Epeli Hau'ofa. Suva: University of the South Pacific, 1993: 2-16. Print.

Ihimaera, Witi, and Long, D. S. "Contemporary Maori Writing: A Context." Into the World of Light: An Anthology of Maori Writing. Ed. Witi Ihimaera and D. S. Long. Auckland: 
Heinemann, 1982. 1-6. Print.

Jackman, Karen. “Odessa's Story.” The New Zealand Listener July 23 (1983): 23-4. Print.

Johnson, Robert. SHE: Understanding Feminine Psychology. New York: Harper and Row, 1989. Print.

King, Thomas. The Truth About Stories: A Native Narrative. Toronto: House of Anansi Press, 2003. Print.

Kuhl, Stefan. The Nazi Connection: Eugenics, American Racism, and German National Socialism. New York: Oxford University Press, 2001. Print.

Lee, Jenny. "Decolonising Māori Narratives: Pūrākau as a Method.” MAI Review 2. 2009

Loader, Arini May. "Haere Mai me Tuhituhi he Pukapuka; Muri Iho ka Whawhai ai Tātou:

Reading Te Rangikāheke.” MA thesis. Victoria University of Wellington, 2008. Print.

Manning, Frederick Edward. Old New Zealand: being Incidents of Native Customs and Character in the Old Times. By A Pakeha Maori'. (1863) Project Gutenberg. 3 Aug 2010. Web. 19 Mar 2013.

Melbourne, Hirini. "Whare Whakaairo: Maori Literary Traditions.” Dirty Silence: Aspects of Language and Literature in New Zealand. Eds. Graham McGregor and Mark Williams. Auckland: Oxford, 1991. 129-41. Print.

Mila, Karlo. Dream Fish Floating. Wellington: Huia, 2005. Print

Moorefield, John C. Māori Dictionary: Te Aka Māori-English, English-Māori Dictionary. n.p. 2003. Web. 1 Feb. 2013.

O'Donnell D, "Re-claiming the 'fob': the immigrant family in Samoan drama." Performing Aotearoa: New Zealand Drama and Theatre in an Age of Transition. Eds. Marc Maufort and David O'Donnell. Brussels: PIE Peter Lang, 2007, 307-330.

Ortiz, Simon J. “They Crossed Country.” Sand Creek. Tuscon: University of Arizona Press, 1981: 46-7. Print.

---. “At the Salvation Army." Sand Creek. Tuscon: University of Arizona Press, 1981. 52-3. Print.

Rich, Paul B. Race and Empire in British Politics. $2^{\text {nd }}$ edition. Cambridge: Cambridge UP, 1990. Print.

Rika -Heke, Powhiri Wharemarama. "Margin or Centre? Let me tell you! In the Land of my Ancestors I am the Centre": Indigenous Writing in Aotearoa.” English Postcoloniality: Literatures from around the World. Eds. Radhika Mohanram and Gita Rajan. London: Greenwood Press, 2006. Print.

Said, Edward. Orientalism. New York: Pantheon, 1978. Print. 
Sallah, Michael and Mitch Weiss. Tiger Force: A True Story of Men and War. New York: Little, Brown and Company, 2006. Print.

Senf, Carol A., "Dracula: The Unseen Face in the Mirror." Journal of Narrative Technique 9.3 Fall 1979: 160-70. Web. 29 July 2012.

Sinavaiana-Gabbard, Caroline. "Introduction: a kind of genealogy." Alchemies of Distance.

Suva: Institute of Pacific Studies, 2001: 11-28. Print.

Smith, Linda Tuhiwai. Decolonizing Methodologies: Research and Indigenous Peoples.

London: Zed Books and Otago UP, 1999. Print.

Spenser, Edmund. "The Legende of the Knight of the Red Crosse, or Of Holinesse." The Works of Edmund Spenser: A Valorium Edition. Eds. Edwin Greenlaw, Charles Grosvenor Osgood, and Fredrick Morgan Padelford, vols I, VIII. Baltimore: The Johns Hopkins Press, 1932, 1938. Print.

Stafford, Jane. "Terminal Creeds and Native Authors." Comparative Approaches to Indigenous Literary Studies. Spec. issue of The Journal of New Zealand Literature 24.2 (2007): 153-84. Print.

Strongman Tribole, Hinauri. "The Offering." Into the World of Light: An Anthology of Maori

Writing. Ed. Witi Ihimaera and D. S. Long. Auckland: Heinemann, 1982. 95-7. Print. Symes, Mary. Grief and Dreams. North Balwyn, Victoria: Rene Gordon, 1987. Print. Swift, Jonathan. Travels into Several Remote Nations of the World. In Four Parts By Lemuel Gulliver, First a Surgeon, and then a Captain of several Ships. 1726-7. "Gulliver's Travels by Jonathan Swift.” Project Gutenberg. 15 June 2009. Web. 27 July 2012.

Te Puni Kōkiri. "Māori Research Agenda on Family Violence." Wellington: Department of Māori Affairs, 2008. Print.

Te Punga Somerville, Alice. Once Were Pacific Māori Connections to Oceania. Minneapolis: University of Minnesota Press, 2012.

---. “'The Historian Who Lost His Memory': A Story about Stories.” Te Pouhere Kōrero 3: Māori History, Māori People.(2009): 63-82. Print.

---. "The Lingering War Captain: Maori Texts, Indigenous Contexts.” Comparative Approaches to Indigenous Literary Studies. Spec. issue of The Journal of New Zealand Literature 24.2 (2007): 20-43. Print.

Thaman, Konai Helu. "Decolonizing Pacific Studies: Indigenous Perspectives, Knowledge and Wisdom in Higher Education.” The Contemporary Pacific 1. Spring (2003): 1-17. Print.

Tuwhare, Hone. "Speak to me, Brother." Small Holes in the Silence: Collected Works. 
Auckland: Random House, 2011. Print.

Waldie, A. J. "John Rutherford: The "White New Zealander"." The New Zealand Railways Magazine 13.81 Nov. (1938): 25-28. NZETC. Web. 19 Mar 2013.

---. "Richard Barrett: Pakeha-Maori.” The New Zealand Railways Magazine 13.2 2 May (1938): 38-40. NZETC. Web. 19 Mar 2013.

Wannen, Rich. “La Casa Del Terror (1960).” IMDb. IMDb, n.d. Web. 9 May 2012.

Ward, Martha C. Poor Women, Powerful Men: America's Great Experiment in Family Planning. Boulder: Westview 1984. Print.

Wendt, Albert. “All Streets Lead." Shaman of Visions. Auckland: AUP, 1984. 54. Print.

---. “Tatauing the Post-colonial Body.” SPAN 42/43: Apr/Oct (1996): 15-29. Reprinted in SPAN 62: Dec (2009): 83-103. Print.

---. The Adventures of Vela. Wellington: Huia, 2009. Print.

---. The Mango's Kiss. Auckland: Vintage, 2003. Print.

---. "Towards a New Oceania." A Pacific Islands Collection. Seaweeds and Constructions 7. 1983. 71-85. Print.

Wells, H. G. The Island of Doctor Moreau. 1896. "Wells, H. G. (Herbert George), 1866-

1946. The Island of Doctor Moreau" Electronic Text Center, University of Virginia Library. 1995. Web. 6 May 2012. 